NBER WORKING PAPER SERIES

\title{
GENERAL EQUILIBRIUM ANALYSIS OF THE EATON-KORTUM MODEL OF INTERNATIONAL TRADE
}

\author{
Fernando Alvarez \\ Robert E. Lucas, Jr. \\ Working Paper 11764 \\ http://www.nber.org/papers/w11764
NATIONAL BUREAU OF ECONOMIC RESEARCH
1050 Massachusetts Avenue
Cambridge, MA 02138
November 2005

We thank Jonathan Eaton, Tim Kehoe, Sam Kortum, Ellen McGrattan, Sergey Mityakov, Casey Mulligan, John Romalis, Kim Ruhl, Ed Prescott, Phil Reny, Rob Shimer, Nancy Stokey, Chad Syverson, Ivan Werning, participants in the December, 2003, conference at Torcuato di Tella and seminar participants at Cornell, Boston University, Brown, Harvard, Minnesota and Chicago for helpful discussions. Constantino Hevia, Natalia Kovrijnykh, and Oleksiy Kryvtsov provided many suggestions and able assistance. The views expressed herein are those of the author(s) and do not necessarily reflect the views of the National Bureau of Economic Research.

(O)2005 by Fernando Alvarez and Robert E. Lucas, Jr. All rights reserved. Short sections of text, not to exceed two paragraphs, may be quoted without explicit permission provided that full credit, including $\odot$ notice, is given to the source. 
A Simple Test of Adverse Events and Strategic Timing Theories of Consumer Bankruptcy Fernando Alvarez and Robert E. Lucas, Jr.

NBER Working Paper No. 11764

November 2005

JEL No. F0, F1

\section{ABSTRACT}

We study a variation of the Eaton-Kortum model, a competitive, constant-returns-to-scale multicountry Ricardian model of trade. We establish existence and uniqueness of an equilibrium with balanced trade where each country imposes an import tariff. We analyze the determinants of the cross-country distribution of trade volumes, such as size, tariffs and distance, and compare a calibrated version of the model with data for the largest 60 economies. We use the calibrated model to estimate the gains of a world-wide trade elimination of tariffs, using the theory to explain the magnitude of the gains as well as the differential effect arising from cross-country differences in preliberalization of tariffs levels and country size.

Fernando Alvarez University of Chicago, Department of Economics

1126 East 59th Street

Social Science Building, Room 442

Chicago, IL 60637

and NBER

f-alvarez1@uchicago.edu

Robert E. Lucas Jr.

Department of Economics The University of Chicago

1126 East 59th Street

Chicago, IL 60637

and NBER

relucas@uchicago.edu 


\section{Introduction}

Eaton and Kortum (2002) have proposed a new theory of international trade, an economical and versatile parameterization of the models with a continuum of tradeable goods that Dornbusch, Fischer, and Samuelson (1977) and Wilson (1980) introduced many years ago. In the theory, constant-returns producers in different countries are subject to idiosyncratic productivity shocks. Buyers of any good search over producers in different countries for the lowest price, and trade assigns production of any good to the most efficient producers, subject to costs of transportation and other impediments. The gains from trade are larger the larger is the variance of individual productivities, which is the key parameter in the model.

The model shares with those of the "new trade theory" the important ability to deal sensibly with intra-industry trade: trade in similar categories of goods between similarly endowed countries. But unlike the earlier theory, the Eaton-Kortum (2002) model is competitive, involving no fixed costs and no monopoly rents. ${ }^{2}$ Of course, fixed costs and monopoly rents are present in reality, but theories based on competitive behavior are much simpler to calibrate and permit the use of a large body of general equilibrium theory to help in analysis.

One aim of this paper is to restate the economic logic of a variation of the Eaton-Kortum model of trade in a particular general equilibrium context. In the next section, we will introduce the basic ideas using a closed economy with a production technology of the Eaton-Kortum type. In Section 3, we define an equilibrium with balanced trade in a world with many countries, each one imposing import tariffs. Section 4 gives sufficient conditions for this equilibrium to exist. The problem of determining whether the equilibrium is unique and of finding an algorithm to compute

\footnotetext{
${ }^{2}$ See, for example, Ethier (1979, 1982), Krugman (1979), Helpman (1981), and the Helpman and Krugman (1985) monograph. Baxter (1992) argues that competitive, Ricardian models are equally capable of dealing realistically with intra-industry trade.
} 
it is addressed in Section 5.

A second goal of the paper is to find out whether the cross-country distribution of trade volumes generated by a model of this type is consistent with the behavior of volumes in the data. In Section 6, we calibrate some of the main parameters of the theory. Section 7 discusses some instructive special cases that are simple enough to work out by hand. Using estimates from Section 6, we examine the implications of these special cases of the theory for the volume of trade, and the way that trade volume behaves as a function of size, and compare these implications to data on total GDP and trade volumes for the 60 largest economies. Sections 8 and 10 go over the same ground numerically with more realistic assumptions. In these two sections we apply the algorithm described in Section 5, calibrate the model to the observed distribution of GDPs and the relative prices of tradeables to non-tradeable goods, and introduce heterogeneity in transportation costs and tariff rates.

Our normative goal is to use the quantitative theory to estimate the welfare gains from hypothetical trade liberalizations. Comparisons between free trade and autarchy are carried out in Sections 7. Section 9 studies the optimal tariff policy of a small economy. We also calculate the effects of a world-wide liberalization in which every country's tariffs are set to zero. We use the theory to explain the magnitude of the average gains of trade, as well as differential effects arising from cross-country differences in pre-liberalization tariff levels and country size. Section 10 also relates the theory to growth accounting: the partitioning of cross-section differences in incomes into their ultimate sources. Conclusions are contained in Section 11.

\section{Preferences, Technology, and Closed Economy Equilibrium}

The Eaton-Kortum model is Ricardian, with a continuum of goods produced under a constant-returns technology. The new idea is a two-parameter probabilistic model that generates the input requirements for producing each good. It will be 
useful to introduce this model of a technology in the simpler context of a single, closed economy before turning to the study of a model of a world of $n$ countries in Section 3.

We develop a purely static model in which labor is the only primary (nonproduced) factor of production, and production requires only labor and produced, intermediate goods as inputs. In the model, there are $L$ consumers, each of whom supplies one unit of labor, to which no disutility is attached, and produces and consumes a single good in quantity $c .{ }^{3}$ This final good is produced with labor services and a symmetric Spence-Dixit-Stiglitz aggregate $q$,

$$
q=\left[\int_{0}^{1} q(u)^{1-1 / \eta} d u\right]^{\eta /(\eta-1)}
$$

of a continuum of produced goods. We call these produced goods "tradeables," with an eye toward the role they will play in later sections.

Individual tradeable goods are in turn produced with labor and the tradeables aggregate (2.1). Thus, consider a given tradeable $q(u)$. Let $s(u)$ be the labor used to produce this good and let $q_{m}(u)$ be the level of the materials aggregate $q$, defined in (2.1), used to produce $q(u)$. The production technology relating these inputs and the output they imply is assumed to be

$$
q(u)=x(u)^{-\theta} s(u)^{\beta} q_{m}(u)^{1-\beta} .
$$

Total factor productivity (TFP) levels $x(u)^{-\theta}$ vary across goods. As in Eaton and Kortum (2002), we model the individual $x(u)$ as independent random variables, exponentially distributed with parameter $\lambda$. These are then amplified in percentage terms

\footnotetext{
${ }^{3}$ We call $L$ population, $p$ the price of the consumption good, $L P c$ total nominal GDP, and $c$ real GDP per capita. This usage will be fine through the development of the theory in Sections 2-5. When we calibrate and apply versions of the model, we will need to interpret these variables more carefully so as to accomodate physical and human capital differences.
} 
by the parameter $\theta \cdot{ }^{4}$ Note that a low $x$-value means a high productivity level (and a low unit cost).

To build a theory on this basis, we need to put enough structure on these functions of $u$ so that the integral in (2.1) has meaning. Instead of doing this directly, we re-label the goods as follows. The only parameter that varies across these goods $u$ is this productivity level $x(u)$, and all goods $q(u)$ enter symmetrically in the aggregate (2.1). It will be convenient, then, simply to re-name each tradeable good by its productivity draw $x$, to re-write the aggregate (2.1) in the form

$$
q=\left[\lambda \int_{0}^{\infty} e^{-\lambda x} q(x)^{1-1 / \eta} d x\right]^{\eta /(\eta-1)}
$$

where $\lambda$ is the parameter of the exponential distribution from which productivities are drawn, and to re-state the production functions of the individual materials as

$$
q(x)=x^{-\theta} s(x)^{\beta} q_{m}(x)^{1-\beta} .
$$

We speak of "good $x$ ", and so on.

It is important to emphasize that these productivity draws $x$ are economy-wide effects. Anyone is free to produce any specific good, and every producer of that good has access to the same production technology (2.3), with the same stochastic intercept $x^{-\theta}$, as other producers do. Since (2.3) is a constant-returns technology the number of firms producing any good will be indeterminate, but whatever that number is, no single producer has any market power and all prices will be set at marginal cost, equivalent to minimum unit cost.

The production of the non-tradeable final good is given by a Cobb-Douglas function of the tradeable aggregate $q_{f}$ and the labor input $s_{f}$ :

$$
c=s_{f}^{\alpha} q_{f}^{1-\alpha} .
$$

\footnotetext{
${ }^{4}$ We are using $\theta$ for the parameter that Eaton and Kortum call $1 / \theta$, so that in this paper a larger $\theta$ means a larger variance in individual productivities.
} 
The labor and tradeables inputs allocated to each production process must sum to the totals available. In per capita terms, this means that

$$
\begin{gathered}
s_{f}+\lambda \int_{0}^{\infty} e^{-\lambda x} s(x) d x=1, \\
q=q_{m}+q_{f},
\end{gathered}
$$

and

$$
q_{m}=\lambda \int_{0}^{\infty} e^{-\lambda x} q_{m}(x) d x .
$$

To sum up, feasible per capita allocations are numbers $y, s_{f}, q, q_{m}$, and $q_{f}$ and functions $s(x), q(x)$, and $q_{m}(x)$ on $\mathbf{R}_{+}$that satisfy (2.2)-(2.7).

Let the prices of individual tradeables be $p(x)$. Producers of all kinds will choose purchases of the individual goods so as to obtain the tradeables aggregate at minimum unit cost $p_{m}$, say. That is, they will solve

$$
p_{m} q=\min _{q(x)} \lambda \int_{0}^{\infty} e^{-\lambda x} p(x) q(x) d x
$$

subject to

$$
\left[\lambda \int_{0}^{\infty} e^{-\lambda x} q(x)^{1-1 / \eta} d x\right]^{\eta /(\eta-1)} \geq q .
$$

This problem is solved by the function

$$
q(x)=\left(\lambda \int_{0}^{\infty} e^{-\lambda x} p(u)^{1-\eta} d u\right)^{\eta / 1-\eta} p(x)^{-\eta} q .
$$

It follows that

$$
p_{m}=\left(\lambda \int_{0}^{\infty} e^{-\lambda x} p(x)^{1-\eta} d x\right)^{1 / 1-\eta} .
$$

The individual production levels can be restated as

$$
q(x)=p_{m}^{\eta} p(x)^{-\eta} q .
$$


Similarly, given the price $w$ of the labor input and the aggregate materials price $p_{m}$, a final goods producer will choose labor and goods inputs so as to minimize the unit cost $p$ of the final good. That is,

$$
p c=\min _{s, q}\left[w s+p_{m} q\right]
$$

subject to

$$
s^{\alpha} q^{1-\alpha} \geq c .
$$

This problem is solved by the values

$$
s_{f}=\left(\frac{\alpha}{1-\alpha}\right)^{1-\alpha}\left(\frac{p_{m}}{w}\right)^{1-\alpha} c
$$

and

$$
q_{f}=\left(\frac{1-\alpha}{\alpha}\right)^{\alpha}\left(\frac{w}{p_{m}}\right)^{\alpha} c
$$

It follows that

$$
p=\alpha^{-\alpha}(1-\alpha)^{-1+\alpha} w^{\alpha} p_{m}^{1-\alpha} .
$$

Finally, given a price $w$ of the labor input and an aggregate tradeable goods price $p_{m}$, any particular tradeable goods producer $x$ will choose labor and goods inputs so as to minimize the unit cost $p(x)$ of his production, $q(x)$. That is, he will solve

$$
p(x) q(x)=\min _{\ell, q}\left[w \ell+p_{m} q\right] \quad \text { subject to } \quad x^{-\theta} \ell^{\beta} q^{1-\beta} \geq q(x) .
$$

This problem is solved by the values

$$
\begin{gathered}
s(x)=x^{\theta}\left(\frac{\beta}{1-\beta}\right)^{1-\beta}\left(\frac{p_{m}}{w}\right)^{1-\beta} q(x) \\
q_{m}(x)=x^{\theta}\left(\frac{1-\beta}{\beta}\right)^{\beta}\left(\frac{w}{p_{m}}\right)^{\beta} q(x)
\end{gathered}
$$

It follows that

$$
p(x)=B x^{\theta} w^{\beta} p_{m}^{1-\beta},
$$


where

$$
B=\beta^{-\beta}(1-\beta)^{-1+\beta}
$$

In this Ricardian model, we can first solve for the equilibrium prices $p, p_{m}$, and $p(x)$ in terms of the wage $w$. Then we can use these prices to calculate equilibrium quantities. Combining (2.8) and (2.15), we have

$$
\begin{gathered}
p_{m}=\left[\lambda \int_{0}^{\infty} e^{-\lambda x}\left(B x^{\theta} w^{\beta} p_{m}^{1-\beta}\right)^{1-\eta} d x\right]^{1 /(1-\eta)} \\
=B w^{\beta} p_{m}^{1-\beta} \lambda^{-\theta}\left[\int_{0}^{\infty} e^{-z} z^{\theta(1-\eta)} d z\right]^{1 /(1-\eta)},
\end{gathered}
$$

using the change of variable $z=\lambda x$. We write $A(\theta, \eta)$, or sometimes just $A$, for

$$
A(\theta, \eta)=\left[\int_{0}^{\infty} e^{-z} z^{\theta(1-\eta)} d z\right]^{1 /(1-\eta)}
$$

The integral in brackets is the Gamma function $\Gamma(\xi)$, evaluated at the argument $\xi=1+\theta(1-\eta)$. Convergence of the integral requires

$$
1+\theta(1-\eta)>0
$$

which we assume to hold throughout this paper. ${ }^{5}$ In terms of $A,(2.16)$ can be written as

$$
p_{m}=A B w^{\beta} p_{m}^{1-\beta} \lambda^{-\theta}
$$

and solving for $p_{m}$ yields

$$
p_{m}=(A B)^{1 / \beta} \lambda^{-\theta / \beta} w .
$$

\footnotetext{
${ }^{5}$ If $\eta$ were too large to satisfy (2.17), the integral in (2.16) would not converge. Economically, this would mean unbounded production of the tradeable aggregate, as labor is concentrated on goods where $x$ is near zero (where $x^{-\theta}$ is very high). Changes in the parameter $\eta$ will affect the units in which tradeables are measured, and hence relative prices that depend on these units. The allocation of labor and materials between the two sectors is independent of the value of $\eta$. See note 7 .
} 
Substituting from (2.18) back into (2.15) then yields the prices of individual tradeables:

$$
p(x)=A^{(1-\beta) / \beta} B^{1 / \beta} x^{\theta} \lambda^{-\theta(1-\beta) / \beta} w .
$$

The price of the final good is, from (2.12) and (2.18),

$$
p=\alpha^{-\alpha}(1-\alpha)^{-1+\alpha}(A B)^{(1-\alpha) / \beta} \lambda^{-\theta(1-\alpha) / \beta} w .
$$

Notice that all these prices, $p, p_{m}$, and $p(x)$ are different multiples of the wage rate $w$. This is a labor theory of value: Everything is priced according to its labor content.

The shares of labor and materials inputs in the output value of each tradeable good $x$ are $\beta$ and $1-\beta$ respectively. Then the same equality must obtain for the aggregates:

$$
\beta=\frac{w\left(1-s_{f}\right)}{p_{m} q} \quad \text { and } \quad 1-\beta=\frac{q_{m}}{q} .
$$

Using (2.6) we have $q_{f}=\beta q$ and then the relative price formula (2.18) gives

$$
1-s_{f}=(A B)^{1 / \beta} \lambda^{-\theta / \beta} q_{f} .
$$

A second equation involving $s_{f}$ and $q_{f}$ is obtained from (2.10) and (2.11):

$$
\frac{s_{f}}{q_{f}}=\left(\frac{\alpha}{1-\alpha}\right)\left(\frac{p_{m}}{w}\right) .
$$

Using (2.18) again,

$$
\frac{s_{f}}{q_{f}}=\left(\frac{\alpha}{1-\alpha}\right)(A B)^{1 / \beta} \lambda^{-\theta / \beta} .
$$

The two equations (2.22) and (2.23) can be solved for $s_{f}$ and $q_{f}$ :

$$
s_{f}=\alpha
$$

and

$$
q_{f}=(1-\alpha)(A B)^{-1 / \beta} \lambda^{\theta / \beta} .
$$


From these equations, all equilibrium quantities can be calculated, just as equilibrium prices can be calculated from (2.18)-(2.20). National income per capita, in dollars, is $w$, and this must equal per capita nominal GDP, $p c$. Multiplying the figures by $L$ gives the economy totals. Real GDP per capita, which equals utility in the units we are using, is

$$
c=\frac{w}{p}=\alpha^{\alpha}(1-\alpha)^{1-\alpha}(A B)^{-(1-\alpha) / \beta} \lambda^{\theta(1-\alpha) / \beta},
$$

using (2.20).

\section{General Equilibrium}

The technology proposed by Eaton and Kortum for the production of tradeables, described in the last section, involves a continuum of goods, produced under constant returns with labor requirements that vary in a smooth, exogenously given way, defined by the parameter pair $(\lambda, \theta)$. This is a close descendant case of the technologies proposed by Dornbusch, Fischer, Samuelson (1977) and Wilson (1980). An international trade theory based on this technology can thus be developed along the lines of these papers.

Specifically, we consider an equilibrium in a world of $n$ countries, all with the structure described in Sections 2, in which trade is balanced. Let total labor endowments be $L=\left(L_{1}, \ldots, L_{n}\right)$, where $L_{i}$ is the total units of labor in $i$. The exponential distributions that define each country's technology have the parameters $\lambda=\left(\lambda_{1}, \ldots, \lambda_{n}\right)$. Labor is not mobile. We use $w=\left(w_{1}, \ldots, w_{n}\right)$ for the vector of wages in the individual countries. Preferences and the technology parameters $\theta, \beta, \alpha$ and $\eta$ are common to all countries. The structure of production in each country is exactly as described in Section 2, except that now tradeables are traded, subject to transportation costs and tariffs. 
Transportation costs are defined in physical, "iceberg" terms: we assume that one unit of any tradeable good shipped from $j$ to $i$ results in $\kappa_{i j}$ units arriving in $i$. Interpreting the terms $\kappa_{i j}$ as representing costs that are proportional to distance, it is natural to assume that $\kappa_{i j}>0, \kappa_{i j} \leq 1$, with equality if $i=j, \kappa_{i j}=\kappa_{j i}$ for all $i, j$, and

$$
\kappa_{i j} \geq \kappa_{i k} \kappa_{k j} \text { for all } i, j, k \text {. }
$$

We also want to consider tariffs that distort relative prices but do not entail a physical loss of resources. In practice, trade barriers take many forms, but here we consider only flat rate tariffs levied by country $i$ on goods imported from $j$, and where the proceeds are rebated as lump sum payments to the people living in $i$. Define $\omega_{i j}$ to be the fraction of each dollar spent in $i$ on goods made in $j$ that arrives as payment to a seller in $j$.

In the closed economy analysis of Section 2 we exploited the assumptions of competition and constant returns to solve for all equilibrium prices as multiples of the wage $w$, with coefficients depending only on the technology. With this done, we then calculated equilibrium quantities. This same two-stage procedure can be applied to the case of many countries, though of course each stage is more complicated.

A new notation for the commodity space is needed. Let $x=\left(x_{1}, \ldots, x_{n}\right)$ be the vector of technology draws for any given tradeable good for the $n$ countries. We refer to "good $x$," as before, but now $x \in \mathbf{R}_{+}^{n}$. Assume that these draws are independent across countries, so that the joint density of $x$ is

$$
\phi(x)=\left(\prod_{i=1}^{n} \lambda_{i}\right) \exp \left\{-\sum_{i=1}^{n} \lambda_{i} x_{i}\right\}
$$

Use $q_{i}(x)$ for the consumption of tradeable good $x$ in country $i$, and $q_{i}$ for consumption in $i$ of the aggregate,

$$
q_{i}=\left[\int q_{i}(x)^{1-1 / \eta} \phi(x) d x\right]^{\eta /(\eta-1)} .
$$


(Here $\int$ denotes integration over $\mathbf{R}_{+}^{n}$.) Let $p_{i}(x)$ be the prices paid for tradeable good $x$ by producers in $i$. Let

$$
p_{m i}=\left[\int p_{i}(x)^{1-\eta} \phi(x) d x\right]^{1 /(1-\eta)}
$$

be the price in $i$ for a unit of the aggregate. Analogous to (2.9), we have

$$
q_{i}(x)=p_{m i}^{\eta} p_{i}(x)^{-\eta} q_{i}, \quad i=1, \ldots, n .
$$

The tradeable good $x=\left(x_{1}, \ldots, x_{n}\right)$ is available in $i$ at the unit prices

$$
B x_{1}^{\theta} w_{1}^{\beta} p_{m 1}^{1-\beta} \frac{1}{\kappa_{i 1} \omega_{i 1}}, \ldots, B x_{n}^{\theta} w_{n}^{\beta} p_{m n}^{1-\beta} \frac{1}{\kappa_{i n} \omega_{i n}},
$$

which reflect both production costs (labor and intermediate inputs) and transportation and tariff costs. All producers in $i$ buy at the same, lowest price:

$$
p_{i}(x)=B \min _{j}\left[\frac{w_{j}^{\beta} p_{m j}^{1-\beta}}{\kappa_{i j} \omega_{i j}} x_{j}^{\theta}\right] .
$$

Note that without assumption (3.1), the right side of (3.4) would not necessarily be the least cost way of obtaining good $x$ in country $i$.

The price index $p_{m i}$ of tradeables in $i$ must be calculated country by country. We derive an expression for $p_{m i}$ from (3.2) and (3.4). The derivation uses two well-known properties of the exponential distribution:

$$
x \sim \exp (\lambda) \quad \text { and } \quad k>0 \quad \Rightarrow \quad k x \sim \exp \left(\frac{\lambda}{k}\right)
$$

and

$$
\begin{gathered}
x \text { and } y \text { independent, } x \sim \exp (\lambda), y \sim \exp (\mu), \\
\quad \text { and } z=\min (x, y) \quad \Rightarrow \quad z \sim \exp (\lambda+\mu) .
\end{gathered}
$$

From (3.2), we have

$$
p_{m i}^{1-\eta}=\int p_{i}(x)^{1-\eta} \phi(x) d x
$$


and note that the right side is the expected value of the random variable $p_{i}(x)^{1-\eta}$. From (3.4)

$$
p_{i}(x)^{1 / \theta}=B^{1 / \theta} \min _{j}\left[\frac{w_{j}^{\beta / \theta} p_{m j}^{(1-\beta) / \theta}}{\left(\kappa_{i j} \omega_{i j}\right)^{1 / \theta}} x_{j}\right] .
$$

Property (3.5) implies that $z_{j} \equiv w_{j}^{\beta / \theta} p_{m j}^{(1-\beta) / \theta}\left(\kappa_{i j} \omega_{i j}\right)^{-1 / \theta} x_{j}$ is exponentially distributed with parameter

$$
\psi_{i j}=\left(\frac{w_{j}^{\beta} p_{m j}^{1-\beta}}{\kappa_{i j} \omega_{i j}}\right)^{-1 / \theta} \lambda_{j}
$$

and property (3.6) implies that $z \equiv \min _{j} z_{j}$ is exponentially distributed with parameter $\sum_{j=1}^{n} \psi_{i j}$. Applying (3.2) again, this proves that $p_{i}(x)^{1 / \theta}$ is exponentially distributed with parameter

$$
\mu=B^{-1 / \theta} \sum_{j=1}^{n} \psi_{i j}
$$

It then follows from (3.7) that

$$
p_{m i}^{1-\eta}=\mu \int_{0}^{\infty} u^{\theta(1-\eta)} e^{-\mu u} d u .
$$

Using the change of variable $z=\mu u$, we have that

$$
\begin{aligned}
p_{m i}^{1-\eta} & =\mu^{-\theta(1-\eta)} \int_{0}^{\infty} e^{-z} z^{\theta(1-\eta)} d z \\
& =\mu^{-\theta(1-\eta)} A^{1-\eta}
\end{aligned}
$$

where $A=A(\theta, \eta)$ is the constant defined in Section 2. Then

$$
p_{m i}(w)=A B\left(\sum_{j=1}^{n} \psi_{i j}\right)^{-\theta} \equiv A B\left(\sum_{j=1}^{n}\left(\frac{w_{j}^{\beta} p_{m j}(w)^{1-\beta}}{\kappa_{i j} \omega_{i j}}\right)^{-1 / \theta} \lambda_{j}\right)^{-\theta},
$$

$i=1, \ldots, n$.

We view (3.9) as $n$ equations in the prices $p_{m}=\left(p_{m 1}, \ldots, p_{m n}\right)$, to be solved for $p_{m}$ as a function of the wage vector $w$. It is the same formula as (7) and (9) in Eaton and Kortum (2002). The solution to (3.9), which will be studied in detail in Section 
4, is the analogue to (2.19) in Section 2. Notice that the country identifier $i$ appears on the right side of (3.9) only via the parameters $\kappa_{i j}$ and $\omega_{i j}$.

Next we calculate the tradeables expenditure shares for each country $i$ : The fraction $D_{i j}$ of country $i^{\prime}$ s total per capita spending $p_{m i} q_{i}$ on tradeables that is spent on goods from country $j$. Economically, the total spending in $i$ on goods from $j$ is just

$$
p_{m i} q_{i} D_{i j}=\int_{\mathbf{B}_{i j}} p_{i}(x) q_{i}(x) \phi(x) d x,
$$

where $\mathbf{B}_{i j} \subset \mathbf{R}_{+}^{n}$ is the set on which $j$ attains the minimum in (3.4). Using (3.3) and (3.4), this integral can be evaluated to obtain the expression (3.11) (below) for $D_{i j}$.

One can also show that the $D_{i j}$ will simply be the probabilities that for a particular good $x$, the low price vendor for buyers in $i$ are sellers in $j$. These probabilities can be calculated directly, using a third fact about exponential distributions:

$x$ and $y$ independent, $x \sim \exp (\lambda)$, and $y \sim \exp (\mu)$

$$
\Rightarrow \quad \operatorname{Pr}\{x \leq y\}=\frac{\lambda}{\lambda+\mu}
$$

From (3.4) we have

$$
\begin{aligned}
D_{i j} & =\operatorname{Pr}\left\{\frac{w_{j}^{\beta} p_{m j}^{1-\beta}}{\kappa_{i j} \omega_{i j}} x_{j}^{\theta} \leq \min _{k \neq j}\left[\frac{w_{k}^{\beta} p_{m k}^{1-\beta}}{\kappa_{i k} \omega_{i k}} x_{k}^{\theta}\right]\right\} \\
& =\operatorname{Pr}\left\{\left(\frac{w_{j}^{\beta} p_{m j}^{1-\beta}}{\kappa_{i j} \omega_{i j}}\right)^{1 / \theta} x_{j} \leq \min _{k \neq j}\left[\left(\frac{w_{k}^{\beta} p_{m k}^{1-\beta}}{\kappa_{i k} \omega_{i k}}\right)^{1 / \theta} x_{k}\right]\right\} .
\end{aligned}
$$

By (3.5), the random variable on the left of the inequality is exponential with parameter $\psi_{i j}$. By (3.5) and (3.6), the random variable on the right is exponential with parameter $\sum_{k \neq j} \psi_{i k}$, and the two are obviously independent. Thus (3.10) implies

$$
D_{i j}=\frac{\psi_{i j}}{\sum_{k=1}^{n} \psi_{i k}}=(A B)^{-1 / \theta}\left(\frac{w_{j}^{\beta} p_{m j}(w)^{1-\beta}}{p_{m i}(w) \kappa_{i j} \omega_{i j}}\right)^{-1 / \theta} \lambda_{j} .
$$

Note that $\sum_{j} D_{i j}=1$. 
We now impose trade balance. Under this assumption, the dollar payments for tradeables flowing into $i$ from the rest of the world must equal the payments flowing out of $i$ to the rest of the world. Firms in $i$ spend a total of $L_{i} p_{m i} q_{i}$ dollars on tradeables, including both transportation costs and tariff payments. Of this amount,

$$
L_{i} p_{m i} q_{i} \sum_{j=1}^{n} D_{i j} \omega_{i j}
$$

reaches sellers in all countries. (The rest is collected in taxes, and rebated as a lump sum to consumers in $i$.)

Buyers in $j$ spend a total of $L_{j} p_{m j} q_{j} D_{j i}$ dollars for tradeables from $i$, but of this total only

$$
L_{j} p_{m j} q_{j} D_{j i} \omega_{j i}
$$

reaches sellers in $i$. The rest remains in $j$, as rebated tax receipts. Trade balance then requires that the condition

$$
L_{i} p_{m i} q_{i} \sum_{j=1}^{n} D_{i j} \omega_{i j}=\sum_{j=1}^{n} L_{j} p_{m j} q_{j} D_{j i} \omega_{j i}
$$

must hold. Notice that the term $L_{i} p_{m i} q_{i} D_{i i} \omega_{i i}$-country $i$ 's spending on homeproduced tradeables - appears on both sides of (3.12). Cancelling thus yields the usual definition of trade balance: payments to foreigners equal receipts from foreigners.

Our strategy for constructing the equilibrium in this world economy draws on the analysis of a single, closed economy in Section 2. As in that section, we first note that all prices in all countries can be expressed in terms of wages. In the present case, wages are a vector $w=\left(w_{1}, \ldots, w_{n}\right)$ and we express the coefficients $\phi_{i j}$ as functions of $w$ and $p_{m}$, and then use the $n$ equations (3.9) to solve for the prices $p_{m}=\left(p_{m 1}, \ldots, p_{m n}\right)$ as a function $p_{m}(w)$ of wages. This problem is the subject of Theorem 1 in the next section. With tradeables prices expressed as functions of wages (and of the tax rates 
and other parameters involved in (3.9)), (3.11) expresses the expenditure shares $D_{i j}$ as functions of wages and of tax rates, too. Then (3.12) can be viewed as an equation in wages $w$ and the vector $q$ of tradeables consumption per capita.

The impact of the rest of the world on the behavior of individual producers in $i$ is entirely determined by $p_{m i}$. In the absence of taxes - if $\omega_{i j}=1$ for all $i, j$ - the trade balance condition (3.12) reduces to

$$
L_{i} p_{m i} q_{i}=\sum_{j=1}^{n} L_{j} p_{m j} q_{j} D_{j i}
$$

Also in the absence of taxes, the equilibrium quantities can be calculated from the relative price $p_{m i} / w_{i}$, exactly as we did in Section 2. In this case, (2.24) implies that $s_{f i}=\alpha$, and then the share formula (2.21) implies

$$
\beta L_{i} p_{m i} q_{i}=(1-\alpha) L_{i} w_{i}
$$

Applying this fact to both sides of the trade balance condition and cancelling, we obtain

$$
L_{i} w_{i}=\sum_{j=1}^{n} L_{j} w_{j} D_{j i}(w), \quad i=1, \ldots, n .
$$

We do not need to restrict the transportation cost parameters $\kappa_{i j}$ to reduce (3.12) to (3.14) because the effects of these costs are entirely captured in (3.9).

Theorem 2 in the next section provides conditions that ensure that (3.14) has a solution $w$, but since our objective is to be able to analyze the effects of changes in tariff policies, we cannot stop with this special case. Nor can we make use of the share formulas (2.21) to simplify (3.12) in the general case: The presence of indirect business taxes implies that (3.13) will not hold. Taxes appear in (3.9) too, but they appear separately in (3.12) because tax receipts are recycled back to consumers as lump sum transfers. To deal with the general case, it will be useful to review the national income and product accounts for a country $i$. 
TABLE 1

\begin{tabular}{|l|l|}
\hline Value-added in services & Labor income in services \\
\hline$L_{i} p_{i} c_{i}-L_{i} p_{m i} q_{f i}$ & $L_{i} w_{i} s_{i}$ \\
\hline Value-added in tradeables & Labor income in tradeables \\
\hline$\sum_{j} L_{j} p_{m j} q_{j} D_{j i} \omega_{j i}-L_{i} p_{m i} q_{m i}$ & $L_{i} w_{i}\left(1-s_{f_{i}}\right)$ \\
\hline Value-added in importing & Indirect business taxes \\
\hline$L_{i} p_{m i} q_{i}-L_{i} p_{m i} q_{i} \sum_{j} D_{i j} \omega_{i j}$ & $L_{i} p_{m i} q_{i} \sum_{j \neq i} D_{i j}\left(1-\omega_{i j}\right)$ \\
\hline $\mathrm{GDP}$ & Total labor income $p l u s$ indirect taxes \\
\hline$L_{i} p_{i} c_{i}$ & $L_{i} w_{i}+L_{i} p_{m i} q_{i} \sum_{j} D_{i j}\left(1-\omega_{i j}\right)$ \\
\hline
\end{tabular}

Table 1 provides the accounts for country $i$, viewed as a three sector economy. All entries are in dollars. The left side gives value-added in each sector; the right side gives factor payments (labor payments plus indirect business taxes). Two of these sectors are services (final goods) and tradeables. The third is an importing sector, in which firms buy tradeable goods from both home and foreign producers, pay import duties to their own government, and resell the goods to home producers. This is a constant-returns, free-entry activity, so of course selling prices must be marked up exactly to cover the taxes. If $\omega_{i j}=1$, the entries for this sector would be zero in both columns. To verify that the three sector value-added terms sum to GDP, one needs to use the trade balance condition (3.12).

We now use these accounts as an aid in calculating the fraction $s_{f_{i}}$ of country $i$ 's labor used in final goods production. To do this, let

$$
F_{i}(w)=\sum_{j=1}^{n} D_{i j}(w) \omega_{i j}
$$


denote the fraction of country $i$ 's spending on tradeables that reaches producers (as opposed to the home government). We will verify

$$
s_{f_{i}}(w)=\frac{\alpha\left[1-(1-\beta) F_{i}(w)\right]}{(1-\alpha) \beta F_{i}(w)+\alpha\left[1-(1-\beta) F_{i}(w)\right]} .
$$

Evidently, without taxes $F_{i}=1$ and (3.16) implies that $s_{f_{i}}=\alpha$.

To verify (3.16), we use the share formulas from both producing sectors, the resource constraint (2.6) on tradeables, and the trade balance condition (3.10). The share formulas in final goods production are

$$
w_{i} s_{f_{i}}=\alpha p_{i} c_{i} \quad \text { and } \quad p_{m i} q_{f i}=(1-\alpha) p_{i} c_{i},
$$

implying that

$$
w_{i} s_{f_{i}}=\frac{\alpha}{1-\alpha} p_{m i} q_{f i} .
$$

The share formulas for tradeables production are

$$
L_{i} w_{i}\left(1-s_{f_{i}}\right)=\beta \sum_{j=1}^{n} L_{j} p_{m j} q_{j} D_{j i} \omega_{j i}=\beta L_{i} p_{m i} q_{i} F_{i}
$$

and

$$
L_{i} p_{m i} q_{m i}=(1-\beta) \sum_{j=1}^{n} L_{j} p_{m j} q_{j} D_{j i} \omega_{j i}=(1-\beta) L_{i} p_{m i} q_{i} F_{i} .
$$

where the second equality is each line follows from trade balance (3.12) and the definition of $F_{i}$. From (3.19) and the fact that $q_{i}=q_{f i}+q_{m i}$ we have that

$$
q_{f i}=q_{i}\left[1-(1-\beta) F_{i}\right]
$$

Then (3.17) and (3.18) imply

$$
w_{i} s_{f_{i}}=\frac{\alpha}{1-\alpha} p_{m i} q_{i}\left[1-(1-\beta) F_{i}\right],
$$

and (3.21) and (3.18) imply

$$
w_{i}\left(1-s_{f_{i}}\right)=\beta p_{m i} q_{i} F_{i} .
$$


Finally, eliminating $p_{m i} q_{i}$ between (3.21) and (3.22) and simplifying yields (3.16).

We next use the formulas (3.15), (3.16) and (3.22) to reduce the trade balance equation (3.12) to a system of $n$ equations in the $n$ wage rates $w$, just as we derived equations (3.14) for the no-tax special case. From (3.22),

$$
p_{m i} q_{i}=\frac{w_{i}\left(1-s_{f_{i}}\right)}{\beta F_{i}} .
$$

Inserting this expression into (3.12), we have

$$
L_{i} w_{i}\left(1-s_{f_{i}}\right)=\sum_{j=1}^{n} L_{j} \frac{w_{j}\left(1-s_{j}\right)}{F_{j}} D_{j i} \omega_{j i} .
$$

We view solving these equations as finding the zeros of an excess demand system $Z(w):^{6}$

$$
Z_{i}(w)=\frac{1}{w_{i}}\left[\sum_{j=1}^{n} L_{j} \frac{w_{j}\left(1-s_{j}(w)\right)}{F_{j}(w)} D_{j i}(w) \omega_{j i}-L_{i} w_{i}\left(1-s_{f_{i}}(w)\right)\right] .
$$

We sum up this section in the

Definition. An equilibrium is a wage vector $w \in \mathbf{R}_{++}^{n}$ such that $Z_{i}(w)=0$ for $i=1, \ldots, n$, where the functions $p_{m i}(w)$ satisfy $(3.9)$, the functions $D_{i j}(w)$ satisfy (3.11), the functions $F_{i}(w)$ satisfy (3.15), and the functions $s_{f_{i}}(w)$ satisfy (3.16).

As in the closed economy analysis of Section 2, the full set of equilibrium prices and quantities are readily determined once equilibrium wages are known. The unique solution to (3.11), analyzed in Theorem 1 in the next section, gives tradeable goods prices, as we will describe in Theorem 1 in the next section. Then (3.11) describes the allocation of every country's spending on tradeables, and (3.15) and (3.16) give

\footnotetext{
${ }^{6}$ Calling equations (3.24) an "excess demand system" could mislead, since goods prices have been solved for (in terms of wages) and trade balance has been used in its derivation. The equations describe excess demands for each country's labor only, as functions of wages, just as in Wilson (1980). But whatever terminology one prefers, (3.24) has the mathematical properties of excess demand systems that will let us apply standard results from general equilibrium theory.
} 
the equilibrium allocation $s_{f_{i}}$ of labor in country $i$. Then (3.17) and (3.18) determine $q_{i}$ and $q_{f i}$. Final goods production $c_{i}$ is determined by (2.4).

\section{Existence of Equilibrium}

The economy we analyze is specified by the technology parameters $\alpha, \beta, \eta$ and $\theta$, common to all countries, the country-specific populations and technology levels $L=\left(L_{1}, \ldots, L_{n}\right)$ and $\lambda=\left(\lambda_{1}, \ldots, \lambda_{n}\right)$, the transportation parameters $\left[\kappa_{i j}\right]$, and the tax parameters $\left[\omega_{i j}\right]$. All these numbers are strictly positive. Moreover, we impose

\section{Assumptions (A):}

$$
\begin{aligned}
& \alpha, \beta<1, \\
& 1+\theta(1-\eta)>0,
\end{aligned}
$$

and for some numbers $\underline{\kappa}$ and $\underline{\omega}$,

$$
0<\underline{\kappa} \leq \kappa_{i j} \leq 1 \quad \text { and } \quad 0<\underline{\omega} \leq \omega_{i j} \leq 1
$$

Under these assumptions, we study the existence and (in the next section) the uniqueness of solutions to the excess demand system (3.24). Before turning directly to these issues, Theorem 1 characterizes the function $p_{m}(\cdot): \mathbf{R}_{++}^{n} \rightarrow \mathbf{R}_{+}^{n}$ relating tradeable goods prices to wage rates, defined implicitly by equations (3.9). Then Theorem 2 shows that the excess demand system (3.24) satisfies the sufficient conditions for a theorem on the existence of equilibrium in an $n$-good exchange economy. Theorem 3 , in Section 5, gives one set of assumptions that imply that this solution is unique.

To study (3.9), it is convenient to restate (3.8) and (3.9) in terms of the logs $\widetilde{p}_{m i}=\log \left(p_{m i}\right)$ and $\widetilde{w}_{i}=\log \left(w_{i}\right)$ of prices and wages:

$$
\widetilde{p}_{m i}=\log (A B)-\theta \log \left(\sum_{j=1}^{n}\left(\kappa_{i j} \omega_{i j}\right)^{1 / \theta} \exp \left\{-\frac{1}{\theta}\left[(1-\beta) \widetilde{p}_{m j}+\beta \widetilde{w}_{j}\right]\right\} \lambda_{j}\right),
$$

$i=1, \ldots, n$. Define the function $f: \mathbf{R}^{n} \times \mathbf{R}^{n} \rightarrow \mathbf{R}^{n}$ so that these $n$ equations are

$$
\widetilde{p}_{m}=f\left(\widetilde{p}_{m}, \widetilde{w}\right)
$$


Let $S=\left[\xi_{i j}\right]$ be the $n \times n$ matrix with elements

$$
\xi_{i j}=\frac{\left(\kappa_{i j} \omega_{i j}\right)^{1 / \theta}\left(p_{m j}^{1-\beta} w_{j}^{\beta}\right)^{-1 / \theta} \lambda_{j}}{\sum_{k=1}^{n}\left(\kappa_{i k} \omega_{i k}\right)^{1 / \theta}\left(p_{m k}^{1-\beta} w_{k}^{\beta}\right)^{-1 / \theta} \lambda_{k}},
$$

so that

$$
\frac{\partial f_{i}\left(\widetilde{p}_{m}, \widetilde{w}\right)}{\partial \widetilde{p}_{m j}}=(1-\beta) \xi_{i j} .
$$

The Jacobian of the system $\widetilde{p}_{m}-f\left(\widetilde{p}_{m}, \widetilde{w}\right)$ with respect to $\widetilde{p}_{m}$ is then $I-(1-\beta) S$. We note that $S$ is a stochastic matrix $\left(\xi_{i j}>0\right.$ for all $i, j$ and $\sum_{j} \xi_{i j}=1$ for all $i$ ) and that $\beta \in(0,1)$, so that the inverse of this Jacobean is the strictly positive matrix

$$
[I-(1-\beta) S]^{-1}=\sum_{i=0}^{\infty}(1-\beta)^{i} S^{i} .
$$

If (3.9) has a differentiable solution $\widetilde{p}_{m}(\widetilde{w})$, its derivatives are given by the formulas

$$
\frac{\partial \widetilde{p}_{m}}{\partial \widetilde{w}_{k}}=[I-(1-\beta) S]^{-1} \beta \xi_{k},
$$

where $\xi_{k}=\left(\xi_{1 k}, \ldots, \xi_{n k}\right)$ denotes the $k$-th column of $S$.

Theorem 1. Under the assumptions (A), for any $w \in \mathbf{R}_{++}^{n}$ there is a unique $p_{m}(w)$ that satisfies (3.9). For each $i$, the function $p_{m i}(w)$ is

(i) continuously differentiable on $\mathbf{R}_{++}^{n}$,

(ii) homogenous of degree one,

(iii) strictly increasing in $w$,

(iv) strictly decreasing in the parameters $\kappa_{i j}$ and $\omega_{i j}$, and

(v) satisfies the bounds

$$
\underline{p_{m}}(w) \leq p_{m i}(w) \leq \overline{p_{m}}(w),
$$

for all $w \in \mathbf{R}_{++}^{n}$, where

$$
\overline{p_{m}}(w)=\left(\frac{A B}{\underline{\kappa \omega}}\right)^{1 / \beta}\left(\sum_{j=1}^{n} w_{j}^{-\beta / \theta} \lambda_{j}\right)^{-\theta / \beta}
$$


and

$$
\underline{p_{m}}(w)=(A B)^{1 / \beta}\left(\sum_{j=1}^{n} w_{j}^{-\beta / \theta} \lambda_{j}\right)^{-\theta / \beta} ;
$$

(vi) the derivatives of $\widetilde{p}_{m}(\widetilde{w})$ satisfy

$$
\underline{\xi}_{k} \leq \frac{\partial \widetilde{p}_{m i}(\widetilde{w})}{\partial \widetilde{w}_{k}} \leq \bar{\xi}_{k}
$$

where for each $k, \underline{\xi}_{k}=\min _{i} \xi_{i k}$ and $\bar{\xi}_{k}=\max _{i} \xi_{i k}$.

Proof. That the homogeneity and monotonicity properties (ii), (iii) and (iv) must hold for any solution is evident from the properties of the functions $f_{i}\left(\widetilde{p}_{m}, \widetilde{w}\right)$ in $w, \kappa_{i j}, \omega_{i j}$, and $p_{m i}$. To verify the bounds (v), note first that if $\kappa_{i j} \omega_{i j}=a$ for all $i, j$ for any constant $a$ then (3.9) is solved by

$$
p_{m i}(w)=\left(\frac{A B}{a}\right)^{1 / \beta}\left(\sum_{j=1}^{n} w_{j}^{-\beta / \theta} \lambda_{j}\right)^{-\theta / \beta}
$$

for all $i$. This fact together with properties (iii) and (iv) implies that any solution to (3.9) must satisfy the bounds (v).

For given $w \in \mathbf{R}_{++}^{n}$ define the set $\mathbf{C}$ by

$$
\mathbf{C}=\left\{z \in \mathbf{R}^{n}: \log \left(\underline{p_{m}}(w)\right) \leq z_{i} \leq \log \left(\overline{p_{m}}(w)\right), \text { all } i\right\}
$$

Under the sup norm

$$
\|z\|=\max _{i}\left|z_{i}\right|
$$

$\mathbf{C}$ is compact. We first show that $f(\cdot, \widetilde{w}): \mathbf{C} \rightarrow \mathbf{C}$. To see this, we write $f(z, \widetilde{w} ; \omega, \kappa)$ to emphasize the dependence on $\omega$ and $\kappa$. Then for any $z \in \mathbf{C},(\omega, \kappa)$ and $\widetilde{w}$, we have

$$
\log \left(\overline{p_{m}}(w)\right)=f\left(\log \left(\overline{p_{m}}(w)\right), \widetilde{w} ; 1,1\right) \geq f(z, \widetilde{w} ; \omega, \kappa)
$$

using the bounds (v), the monotonicity properties (iv), and the fact that $f$ is increasing in $z$. Likewise,

$$
\log \left(\underline{p_{m}}(w)\right)=f\left(\log \left(\underline{p_{m}}(w)\right), \widetilde{w} ; \underline{\omega}, \underline{\kappa}\right) \leq f(z, \widetilde{w} ; \omega, \kappa) .
$$


We next show that $f(\cdot, \widetilde{w})$ is a contraction on $\mathbf{C}$ by verifying the Blackwell sufficient conditions. We have already observed that $f(\cdot, \widetilde{w})$ is monotone. Let $a>0$ and apply the mean value theorem to obtain

$$
\begin{aligned}
f_{i}(z+a) & =f_{i}(z)+\sum_{j=1}^{n} \frac{\partial f_{i}}{\partial z_{j}}(z+a(1-v)) a \\
& =f_{i}(z)+(1-\beta) a \sum_{j=1}^{n} \xi_{i j} \\
& =f_{i}(z)+(1-\beta) a,
\end{aligned}
$$

using the formula below (4.2) and the fact that $\sum_{j} \xi_{i j}=1$ for all $i$. Thus $f(\cdot, \widetilde{w})$ has the discounting property

$$
f_{i}(z+a) \leq f_{i}(z)+(1-\beta) a
$$

The contraction mapping theorem then implies the existence of a unique fixed point $\widetilde{p}_{m}(\widetilde{w})$ for $f$ and a unique solution $p_{m}(w)$ to $(3.9)$.

The Jacobian of the system (4.1) has the inverse (4.3), so the implicit function theorem implies that $\widetilde{p}_{m}(\widetilde{w})$ is continuously differentiable everywhere. To verify the bounds (vi), we use the fact that $\bar{\xi}_{k}$ is the largest coordinate in $\xi_{k}$ and write $\xi_{k} \leq \iota \bar{\xi}_{k}$, where $\iota$ is a vector of ones. Thus (4.4) implies

$$
\frac{\partial \widetilde{p}_{m}}{\partial \widetilde{w}_{k}} \leq[I-(1-\beta) S]^{-1} \beta \iota \bar{\xi}_{k} .
$$

Now $S \iota=\iota$, since $S$ is a stochastic matrix, implying that

$$
[I-(1-\beta) S] \iota=\beta \iota
$$

or that

$$
[I-(1-\beta) S]^{-1} \beta \iota=\iota
$$

Thus (4.8) is equivalent to

$$
\frac{\partial \widetilde{p}_{m}}{\partial \widetilde{w}_{k}} \leq \iota \bar{\xi}_{k}
$$


This verifies the upper bound in (4.7). An analogous argument shows that

$$
\frac{\partial \widetilde{p}_{m}}{\partial \widetilde{w}_{k}} \geq \iota \underline{\xi}_{k} .
$$

This completes the proof of Theorem 1 .

To prove that an equilibrium exists, we will apply an existence theorem for an exchange economy with $n$ goods to the demand system $Z(w)$ defined in (3.24).

Theorem 2: Under assumptions (A) there is a $w \in \mathbf{R}_{++}^{n}$ such that

$$
Z(w)=0
$$

Proof. We verify that $Z(w)$ has the properties

(i) $Z(w)$ is continuous,

(ii) $Z(w)$ is homogeneous of degree zero,

(iii) $w \cdot Z(w)=0$ for all $w \in \mathbf{R}_{++}^{n} \quad$ (Walras's Law),

(iv) for $k=\max _{j} L_{j}>0, Z_{i}(w)>-k$ for all $i=1, \ldots, n$ and $w \in \mathbf{R}_{++}^{n}$,

and

(v) if $w^{m} \rightarrow w^{0}$, where $w^{0} \neq 0$ and $w_{i}^{0}=0$ for some $i$, then

$$
\max _{j}\left\{Z_{j}\left(w^{m}\right)\right\} \rightarrow \infty
$$

Then the result will follow from Proposition 17.C.1 of Mas-Colell, Whinston, and Green (1995), p. 585.

(i) The continuity of $p_{m i}$ is part (i) of Theorem 1. The continuity of the functions $D_{i j}$ is then evident from (3.8) and (3.11). The functions $F_{i}$ defined in (3.15) are continuous, and are uniformly bounded from below by $\underline{\omega}$. The functions $s_{f_{i}}$ defined in (3.16) are continuous. The continuity of $Z$ then follows from (3.24).

(ii) From Theorem 1, $p_{m i}$ is homogeneous of degree one. Then (3.8) and (3.11) imply that the $D_{i j}$ are homogeneous of degree zero, and it is immediate that $F_{i}, s_{f_{i}}$, and $Z_{i}$ all have this property. 
(iii) To verify Walras's Law, restate (3.24) as

$$
w_{i} Z_{i}=\sum_{j=1}^{n} L_{j} w_{j}\left(1-s_{j}\right) \frac{1}{F_{j}} D_{j i} \omega_{j i}-L_{i} w_{i}\left(1-s_{f_{i}}\right)
$$

and sum over $i$ to get:

$$
\begin{gathered}
\sum_{i=1}^{n} w_{i} Z_{i}=\sum_{i=1}^{n} \sum_{j=1}^{n} L_{j} w_{j}\left(1-s_{j}\right) \frac{1}{F_{j}} D_{j i} \omega_{j i}-\sum_{i=1}^{n} L_{i} w_{i}\left(1-s_{f_{i}}\right) \\
=\sum_{j=1}^{n} L_{j} w_{j}\left(1-s_{j}\right) \sum_{i=1}^{n} \frac{1}{F_{j}} D_{j i} \omega_{j i}-\sum_{i=1}^{n} L_{i} w_{i}\left(1-s_{f_{i}}\right)=0
\end{gathered}
$$

using (3.15).

The proofs of parts (iv) and (v) are in Appendix A.

\section{Uniqueness and Computation of Equilibrium}

In this section we establish a sufficient condition for the equilibrium of Section 4 to be unique. To do so, we add to Assumption (A) the assumption that the import duties $\omega_{i j}$ levied by country $i$ are uniform over all source countries $j$, so that we write $\omega_{i j}=\omega_{i}$ for $i \neq j$ and $\omega_{i i}=1$. The main result of this section is

Theorem 3. If assumptions (A) hold, if $\omega_{i j}=\omega_{i}$ for all $i \neq j$, and if

$$
\begin{gathered}
(\underline{\kappa \omega})^{2 / \theta} \geq 1-\beta, \\
\alpha \geq \beta,
\end{gathered}
$$

and

$$
1-\underline{\omega} \leq \frac{\theta}{\alpha-\beta}
$$

there is exactly one solution to $Z(w)=0$ that satisfies $\sum_{i=1}^{n} w_{i}=1$.

Proof. In Appendix B, we use the results from Theorem 1, (iii) and (v), to establish that $Z$ has the gross substitute property:

$$
\frac{\partial Z_{i}(w)}{\partial w_{k}}>0 \quad \text { for all } i, k, \quad i \neq k, \quad \text { for all } w \in \mathbf{R}_{++.} \text {. }
$$


(Since $Z$ is homogeneous of degree zero, (5.7) will imply that

$$
\left.\frac{\partial Z_{i}(w)}{\partial w_{i}}>0 \text { for all } i \text {, for all } w \in \mathbf{R}_{++} .\right)
$$

Then the result will follow from Proposition 17.F.3 of Mas-Colell, Whinston, and Green (1995), p. 613.

Direct inspection of the sufficient conditions (5.4) and (5.6) shows that they are satisfied if the tariff and transportation costs are small enough, that is if $\underline{\omega}$ and $\underline{\kappa}$ are close enough to one. For the parameter values for $\alpha, \beta$ and $\theta$ proposed in Section 6, conditions (5.4) and (5.6) are only satisfied for small tariffs. For instance, if $\alpha=0.75, \beta=0.5$ and $\theta=0.15$, condition (5.4) is satisfied if tariffs and transportation cost are no higher than $2.5 \%$ each (i.e. $\underline{\kappa \omega} \geq 0.95$ ). For the same parameters, condition (5.6) is satisfied if tariffs are no higher than $40 \%$ (i.e. $\underline{\omega} \geq 0.6$ ). Condition (5.5), requiring $\alpha>\beta$, is easily satisfied for the benchmark calibration presented later on.

Of course, the conditions (5.4)-(5.6) are sufficient, not necessary, conditions for the gross substitute property to obtain. For the case of two countries, it can be shown that (5.6) alone is sufficient and (5.4) and (5.5) are not required at all. Our numerical experience also confirms that the gross substitutes property holds under much wider conditions than (5.4)-(5.6), including quite high tariff and transportation costs.

We finish this section by discussing the algorithm that we use to compute equilibrium. The gross substitutes property established in Theorem 3 suggests the use of a discrete time analogue of the continuous time tatonnement process. Let $\Delta_{w}$ be defined as

$$
\Delta_{w}=\left\{w \in \mathbf{R}_{+}^{n}: \sum_{i=1}^{n} w_{i} L_{i}=1\right\} .
$$

Then we define the function $T$, mapping $\Delta_{w}$ into itself as follows:

$$
T(w)_{i}=w_{i}\left(1+\nu Z_{i}(w) / L_{i}\right), \quad i=1, \ldots, n,
$$


where $\nu$ is an arbitrary constant satisfying $\nu \in(0,1]$. To interpret (5.8), notice that $Z_{i}(w) / L_{i}$ is country $i^{\prime} s$ labor excess demand per unit of labor. Thus, $T$ prescribes that the percentage increase in country $i$ 's wage be in proportion to a scaled version of country $i$ 's excess demand. To see that $T: \Delta_{w} \rightarrow \Delta_{w}$, note first that $T(w)_{i} \geq 0$ if $1+\nu Z_{i}(w) / L_{i} \geq 0$, since $Z_{i}$ is bounded below by $-L_{i}$ by part (iv) of Theorem 2 . Note second that for any $w \in \Delta_{w}$

$$
\sum_{i=1}^{n} T(w)_{i} L_{i}=\sum_{i} w_{i}\left(1+\nu \frac{Z_{i}}{L_{i}}\right) L_{i}=\sum_{i=1}^{n} w_{i} L_{i}+\nu \sum_{i=1}^{n} w_{i} Z_{i}(w)=1
$$

where the last equality uses Walras' Law. To calculate $T(w)$ numerically, one first needs to calculate $p_{m}(w)$, the solution to (3.11). We used an algorithm based on the contraction property of the function $f$, defined in (4.1) and used to prove Theorem 1.

This function $T$ is closely related to a continuous time version of the tatonnement process. To see this, interpret $T$ dynamically as giving the value $T(w)$ to $w(t+\nu)$ whenever $w(t)$ takes the value $w$. Then (5.8) becomes

$$
\frac{1}{w_{i}(t)} \frac{w_{i}(t+\nu)-w_{i}(t)}{\nu}=\frac{Z_{i}(w(t))}{L_{i}} .
$$

Letting $\nu \rightarrow 0$, we obtain

$$
\frac{d \log w_{i}(t)}{d t}=\frac{Z_{i}(w(t))}{L_{i}} .
$$

Although (5.9) differs from the standard tatonnement process, given by $d w_{i} / d t=$ $c_{i} Z\left(w_{i}(t)\right)$ for some constant $c_{i}$, it has the same stability properties : If $Z$ satisfies the gross substitute property, the differential equation (5.9) converges globally to the unique equilibrium wage. A proof that (5.9) converges to the unique equilibrium can be constructed by showing that $\mathcal{L}(w)=\max _{i}\left\{Z_{i}(w) / L_{i}\right\}$ is a Lyapounov function for this system. In our computational experiments, we found that setting the parameter $\nu$ of (5.8) equal to one always produced monotone convergence, in the sense of sequences with decreasing Lyapounov functions $\mathcal{L}(w)$. 


\section{Calibration}

The general structure of the theory is now in place. In the rest of the paper, we will use a series of algebraic examples and numerical simulations to get an understanding of the properties of the model, of its ability to account for some of the main features of world trade, and of its implications for the effects of some simulated policy changes. We intend these inquiries to be quantitative, so we will need estimated values for the parameters $\theta, \alpha, \beta$ and $\eta$ that are assumed to be constant across economies, and for the endowments $L=\left(L_{1}, \ldots, L_{n}\right)$, the technology parameters $\lambda=\left(\lambda_{1}, \ldots, \lambda_{n}\right)$, and the matrices $\left[\kappa_{i j}\right]$ and $\left[\omega_{i j}\right]$ that describe transportation costs and tariff policies.

For the substitution parameter $\eta$ used in forming the tradeables aggregate, we used a conventional value of 2 : The results we report are not at all sensitive to this choice. $^{7}$ For $\alpha$ and $\beta$, we use the estimates 0.75 and 0.5 , based on U.S. Bureau of Economic Analysis data and related data from other countries from the United Nations and the World Bank. Conceptually, in our theory, $\beta$ is the share of labor in the total value of tradeables produced, and $\alpha$ is closely related to the fraction $s_{f_{i}}$ of employment that is in the non-tradeables (final goods) sector. We discuss the relationship of these theoretical magnitudes to observation, and then review recent evidence.

The theory divides production into two categories: tradeables and non-tradeables. Provisionally, we used value-added, employment, and capital in agriculture, mining, and manufacturing in the U.S. to estimate value-added, employment, and capital in "tradeables" production. Using the BEA input-output tables, the value-added share of these sectors was about 0.2 for the U.S. for the years 1996-99, consistent with an $\alpha$

\footnotetext{
${ }^{7}$ See note 5 . The parameter $\eta$ does not affect the expenditure shares $D_{i j}$ (see (3.11)), and so does not affect the variables $F_{i}$ and $s_{i}$ (see (3.15) and (3.16)), and so does not affect equilibrium wages (see (3.24)).
} 
value of 0.8 . Using employment shares would yield $\alpha=0.82$, and fixed capital shares would imply $\alpha=0.73$.

In fact, according to World Development Indicators (WDI at http://www.worldbank.org) data for the U.S. for the same years, trade in goods was only about $77 \%$ of total trade (exports plus imports over two) in goods and services. The average of this figure for the countries listed in Table 2 (below) is 0.8. These figures led us to augment the tradeables share to $0.25=.2 / .8$. We use $\alpha=0.75$ in all the simulations reported below.

The United Nations Common Database (UNCDB at http://unstats.un.org) for 1993 reports value-added in agriculture, mining, and manufacturing averaging around 0.3 for the OECD countries, and levels ranging to 0.5 and higher for poorer countries. The OECD input-output tables (http://www.oecd.org) for 1990 imply an $\alpha$ value of .72 for the OECD countries. In short, 0.75 seems a reasonable value for $\alpha$ in the industrialized world. It is a serious overstatement for economies that are still substantially pre-industrial.

To calibrate the parameter $\beta$, we need to think of the primary factor $L_{i}$ as "labor-plus-capital" or perhaps as "equipped labor" and to identify $w_{i} L_{i}$ with total value added, not just compensation of employees. Based on the BEA input-output tables for 1996-99, the ratio of value added in manufacturing to the total value of production in this sector was about 0.38 . This figure can be compared to the U.N. (UNIDO Industrial Statistics database) estimate of a world average value of 0.38 in manufacturing for 1998. The OECD input-output table for 1990 gives an average of 0.38 in agriculture, mining, and manufacturing. Since labor's share in most services is higher, including tradeable services in total tradeables would require a higher value of $\beta$. For instance, in the 1997 U.S. input-output table, the average of the ratio of value added to gross product across sectors, weighted by the share of each sector in U.S. exports, is 0.5 . Based on these considerations, we use $\beta=0.5$ throughout this 
paper.

The parameter $\theta$ describing the variability of the idiosyncratic component to productivity is central in quantitative applications of the theory. Its role in the theory is analogous to the role played by elasticities of substitution in theories based on the Armington assumption that goods produced in different countries appear as separate goods in utility functions. In either the Armington context or this one, the estimation of these parameters is related to the estimation of transportation and other costs, since all these factors interact to produce the trade patterns we observe.

Eaton and Kortum (Sections 3-5) obtain joint estimates of $\theta$ and trade cost using a bilateral "gravity" formula implied by the theory and bilateral trade data and prices of individual goods. They obtain an estimate of $\theta=0.12$. Other, similar estimates range from 0.08 to 0.28 . Their estimated trade cost (transportation plus tariffs and other artificial barriers) corresponding to $\theta=0.12$ is large: $28 \%$ for neighboring countries up to $66 \%$ for distant pairs. Anderson and Wincoop (2004) survey analogous bilateral, gravity-type estimates of the (assumed uniform) Armington substitution elasticity. The connection, based on the bilateral gravity formula, is $\theta=1 /(\sigma-1)$, where $\sigma$ is the elasticity. ${ }^{8}$ They conclude, based on several studies, that a reasonable range is $\sigma \in[5,10]$, which corresponds to $\theta \in[0.11,0.25]$. Based on these findings, we report numerical experiments based on $\theta$ values of $0.1,0.15$, and $0.25 .^{9}$

As remarked, the estimation of trade barriers is related to the estimation of $\theta$. Anderson-Wincoop (2004) also report direct evidence of transportation costs - freight charges - on the order of $4 \%$ for the U.S. using trade weights and $11 \%$ for simple averaging. Adding interest costs on cargo in transit may add 9\%. Such estimates applied to the world at large support an estimate of $\kappa=0.9$. This estimate would be

\footnotetext{
${ }^{8}$ See Anderson and Wincoop (2004), pp. 19-22.

${ }^{9}$ More recently, Broda and Weinstein (2005) have estimated import weighted elasticities for the US of 10.35 for the period 1972-88 and of 5.36 for the period 1990-2001 (Table 5).
} 
consistent with a $\theta$ value at the low end of the range we explore. Indirect statistical evidence using distance measures, presence or absence of common borders, and the like can support $\kappa$ values as low as 0.65 . In most of our simulations we used $\kappa=0.75$, applied symmetrically to pairs $i, j$ with $i \neq j$, which is consistent with an intermediate estimate of $\theta$.

Some direct evidence on tariff costs is given in column (4) of our Table 2, described below. They range from $5 \%$ or less for wealthy economies (which account for almost all trade) to as high as $40 \%$ for some poor ones. Values like this show up in many studies. Most experts think that non-tariff barriers are at least as important, but they are hard to quantify. Anderson and Wincoop review evidence from OECD countries, where non-tariff barriers are estimated to be equivalent to an $8 \%$ tariff. In some of our simulations, we assume the value $\omega=0.9$, applied uniformly to all foreign suppliers.

Neither the endowments $L=\left(L_{1}, \ldots, L_{n}\right)$ nor the technology parameters $\lambda=$ $\left(\lambda_{1}, \ldots, \lambda_{n}\right)$ can be observed directly, and the problem of inferring their values from characteristics we can observe will be a focus of Section 8 and 10. Here we simply describe the limited, aggregate data set we use for this and other purposes.

We use the 2002 WDI cdRom to assemble a cross-section of the 59 economies with the largest total GDPs. These countries and the variables measured for each are listed in Table 2. We also include a residual, rest-of-world category (with 5 percent of world GDP), treated as the 60-th economy. Column (1) of the table is the Penn World Table measure of per capita real GDP. We used this variable to order the countries. For each country, five variables are recorded, along with the utility gains from a simulated tariff reform that will be described in Section 9 .

Column (1) is total GDP, denoted $Y=\left(Y_{1}, \ldots, Y_{n}\right)$. These are IMF-based nominal values, converted to U.S. dollars at market exchange rates (where available). They are not on a purchasing power parity basis. In the table they are expressed as fractions of total world GDP. These flows, and all the import and export flows that we 
used were averaged over the years 1994-2000 in order to reduce the importance of trade imbalances and year to year fluctuations, about which the theory evidently has nothing to say.

Column (2) is trade volume, denoted $V=\left(V_{1}, \ldots, V_{n}\right)$, defined as the average of the values of imports and exports, also from the 2002 WDI cdRom, divided by GDP. Both imports and exports are defined to include services as well as goods.

Column (3) reports the ratio of the consumption goods deflator for each country to an index of the prices of machinery and equipment, from the 1996 benchmark year in the Penn World Table. We will use them as observations $P=\left(P_{1}, \ldots, P_{n}\right)$ on the prices $\left(p_{1} / p_{m 1}, \ldots, p_{n} / p_{m n}\right)$ in the theory.

Column (4) of Table 2 lists estimates of average 1996-2000 import tariff rates for each country. These are unweighted averages of ad valorem tariffs applied to different commodities. They are available in the World Bank database "Data on Trade and Import Barriers," and are described in Dollar and Kraay (2004). (For the three countries for which we do not have tariff data, indicated by asterisks, we substituted tariffs from a second source: ratios of import duties to imports, from WDI 2002. For the residual ROW, we used the average of the rest of the column.)

Column (5) contains simulation results that are discussed in Section 9. Column (6) is a 1994-2000 average of per capita income, on a purchasing power basis, from the Penn World Table. This last series is not used in any of the calculations reported below.

\section{INSERT TABLE 2}

\section{Examples}

The algorithm proposed in Section 5 makes it easy to compute equilibria with many countries, differing arbitrarily, but it will be instructive to work through some examples first that are simple enough to solve by hand. We derive the predictions 
of special cases of the theory for the behavior of trade volumes and the gains from trade, as measured by the effects of changes in trade on real consumption.

For future reference, we start with the derivation of some useful formulas for trade volumes and gains, under the assumption - used also in Theorem 3 - that tariffs are uniform: $\omega_{i j}=\omega_{i}$ for all $i \neq j$. We first derive expressions for the value of imports $I_{i}$ and the volume of trade $v_{i}$, defined as the ratio of the value of imports to GDP. The value of imports $I_{i}$ is the fraction of tradeable expenditures bought abroad,

$$
I_{i}=L_{i} p_{m i} q_{i} \sum_{j \neq i} D_{i j}
$$

From the share formula (3.22), using (3.18) to eliminate $s_{f_{i}}$, and collecting terms,

$$
I_{i}=L_{i} w_{i} \frac{(1-\alpha)}{\alpha+(\beta-\alpha) F_{i}}\left(1-D_{i i}\right) .
$$

Now GDP equals wages plus indirect business taxes,

$$
L_{i} p_{i} c_{i}=L_{i} w_{i}+I_{i}\left(1-\omega_{i}\right)
$$

so using the expression (7.1) for imports implies

$$
L_{i} p_{i} c_{i}=L_{i} w_{i}\left[1+\frac{(1-\alpha)\left(1-\omega_{i}\right)}{\alpha+(\beta-\alpha) F_{i}}\left(1-D_{i i}\right)\right] .
$$

Then dividing and using the definition (3.15) of $F_{i}$ and the uniform tariff assumption, we have

$$
v_{i}=\frac{I_{i}}{L_{i} p_{i} c_{i}}=\frac{(1-\alpha)}{\beta\left(D_{i i} /\left(1-D_{i i}\right)+\omega_{i}\right)+1-\omega_{i}} .
$$

Notice that $(1-\alpha) / \beta$ is an upper bound for $v_{i}$.

Using these formulas, we consider first the case of costless trade: $\kappa_{i j}=\omega_{i j}=1$, all $i, j$. This is the analogue of the zero-gravity case analyzed in Section 4.4 of Eaton and Kortum (2002). We solve for each country's wages $w_{i}$, the prices of non-tradeable goods relative to tradeables $p_{i} / p_{m i}$, the shares in world GDP $L_{i} w_{i} / \sum_{j} L_{j} w_{j}$, and the 
volume of trade $v_{i}$, all as functions of the parameters $L_{i}$ and $\lambda_{i}$. With costless trade every country buys the intermediate inputs from the same lowest cost producer, so the $p_{m i}$ are the same for all countries with the common value

$$
p_{m}=(A B)^{1 / \beta}\left(\sum_{j=1}^{n} w_{j}^{-\beta / \theta} \lambda_{j}\right)^{-\theta / \beta} .
$$

Inserting this information into (3.11) yields

$$
D_{i j}(w)=\left(\sum_{k=1}^{n} w_{k}^{-\beta / \theta} \lambda_{k}\right)^{-1} w_{j}^{-\beta / \theta} \lambda_{j} .
$$

Notice that the expenditure shares $D_{i j}$ do not depend on the identity $i$ of the importer.

With $\omega=1$, expression (3.18) gives $s_{f_{i}}=\alpha$, and the excess demand functions (3.24) can now be written

$$
Z_{i}(w)=\left(\frac{1-\alpha}{\beta}\right)\left(\sum_{j=1}^{n} \frac{D_{i j}(w)}{w_{i}} L_{j} w_{j}-L_{i}\right) .
$$

Equating $Z_{i}(w)$ to 0 and applying (7.4), we solve for equilibrium wages

$$
w_{i}=\left(\pi \frac{\lambda_{i}}{L_{i}}\right)^{\theta /(\beta+\theta)}
$$

where the parameter $\pi$, which does not depend on $i$, will be set by whatever normalization we choose for $w$. Compare to equation (22) in Eaton and Kortum (2002).

Setting $\pi=1$, total GDP for country $i$ is

$$
L_{i} w_{i}=L_{i}^{\beta /(\beta+\theta)} \lambda_{i}^{\theta /(\beta+\theta)}
$$

a geometric mean of productivity in tradeables $\lambda_{i}$ and labor in efficiency units $L_{i}$. Notice that if $\theta=0$, so that there is no variation of productivities, then country $i$ 's GDP $L_{i} w_{i}$ is simply $L_{i}$. Using (2.12) and (7.5), the price of the final non-tradeable goods relative to tradeables goods in country $i$ is given by

$$
\frac{p_{i}}{p_{m}}=\alpha^{-\alpha}(1-\alpha)^{-1+\alpha}\left(\frac{\lambda_{i}}{L_{i}}\right)^{\alpha \theta /(\beta+\theta)} p_{m}^{-\alpha},
$$


so that countries with high productivity $\lambda_{i}$ in tradeables have a high relative price of non-tradeables. ${ }^{10}$ From (7.6) and (7.7), we can solve for $L_{i}$ and $\lambda_{i}$ in terms of observables:

$$
L_{i}=\frac{1}{k} Y_{i} P_{i}^{-1 / \alpha}
$$

and

$$
\lambda_{i}=k^{\beta / \theta} Y_{i} P_{i}^{\beta /(\alpha \theta)}
$$

In this world of costless trade, then, data on GDPs $Y_{i}$ and on relative prices $P_{i}$ can be used to infer each country's labor endowment $L_{i}$ and its tradeables productivity parameter $\lambda_{i}$. We will see in Section 10 that the idea of using relative price data $P_{i}$ to separate the effects of $L_{i}$ and $\lambda_{i}$ on production can also be applied in the general case where tariff and transportation costs are positive. The volume of trade $v_{i}$ in the costless trade case is given by

$$
v_{i}=\frac{1-\alpha}{\beta}\left(1-D_{i i}\right)=\frac{1-\alpha}{\beta}\left(1-\frac{L_{i} w_{i}}{\sum_{j} L_{j} w_{j}}\right) .
$$

Our second example explores a different special case. We study a symmetric equilibrium with equal sized countries $L_{i}=L=1$, identical technologies, $\lambda_{i}=\lambda$, and uniform transportation costs and tariffs, described by

$$
\kappa_{i j}=\kappa \quad \text { and } \quad \omega_{i j}=\omega \quad \text { if } \quad i \neq j
$$

and $\kappa_{i i}=\omega_{i i}=1$. In these circumstances, there will be a common equilibrium wage $w_{i}=w$, all $i$. We normalize it to $w=1$. Everyone will face the same tradeables price $p_{m}$, and the formula (3.11) can be solved for

$$
p_{m}=\frac{(A B)^{1 / \beta}}{\left(1+(n-1)(\kappa \omega)^{1 / \theta}\right)^{\theta / \beta} \lambda^{\theta / \beta}} .
$$

\footnotetext{
${ }^{10}$ The idea that countries with a more advanced technology will have a high relative price of non-tradeables is known as the Balassa-Samuelson effect (Balassa (1964), Samuelson (1964)).
} 
The price of final goods is given by $(2.12)$, which with $w=1$ and $p_{m}$ given by $(7.11)$ yields

$$
p=\frac{\alpha^{-\alpha}(1-\alpha)^{-1+\alpha}(A B)^{(1-\alpha) / \beta}}{\left[1+(n-1)(\kappa \omega)^{1 / \theta}\right]^{\theta(1-\alpha) / \beta} \lambda^{\theta(1-\alpha) / \beta}} .
$$

With $w=1,(3.11)$ implies

$$
D_{i j}=\frac{(\kappa \omega)^{1 / \theta}}{1+(n-1)(\kappa \omega)^{1 / \theta}}
$$

for $i \neq j$. Then applying (7.3), the imports/GDP ratio $v$ equals

$$
v=\frac{1-\alpha}{\beta} \frac{(n-1)(\kappa \omega)^{1 / \theta}}{1+(1+\beta \omega-\omega)(n-1)(\kappa \omega)^{1 / \theta} / \beta} .
$$

Nominal GDP per capita in this example is

$$
p c=1+I(1-\omega)=1+v p c(1-\omega),
$$

with $v$ given by (7.13), and consumption, or utility per unit of labor, is given by

$$
c=\frac{1}{1-v(1-\omega)} \frac{1}{p} .
$$

We calculate the utility gain from eliminating a tariff $\omega$. Denote by $c, I$ and $p$ the levels of consumption, imports, and the consumption price corresponding to a tariff $\omega$ and by $c_{0}, I_{0}$ and $p_{0}$ the values corresponding to the case of no tariff: $\omega=1$. Then using (7.12).

$$
\frac{c_{0}}{c}=[1-v(1-\omega)]\left(\frac{\left[1+(n-1) \kappa^{1 / \theta}\right]}{\left[1+(n-1)(\kappa \omega)^{1 / \theta}\right]}\right)^{\theta(1-\alpha) / \beta} .
$$

We use equations (7.13) and (7.15) to derive an expression for the gain $\Lambda \equiv$ $\log \left(c_{0} / c\right)$ of going from pure autarchy, $\omega=0$, to costless trade, $\kappa=\omega=1$. Specializing (7.14) to the autarchy-costless-trade comparison, we get

$$
\Lambda \equiv \log \left(c_{0} / c\right)=\frac{\theta(1-\alpha)}{\beta} \log (n) .
$$


In the last section we argued that the values $\alpha=.75$ and $\beta=.5$ are empirically reasonable, at least for the high income countries. Using the value 0.15 for $\theta,(7.16)$ then implies the gain estimate

$$
\Lambda=(.075) \log (n) .
$$

We can think of $n$ in (7.16) as the ratio of world GDP to the home country's, so that taking values from Table $2, n=3.6 \cong 1 / .28$ for the United States, $n=6.2$ for Japan, and $n=170$ for Denmark. In percentage terms, this formula implies benefits of 10 percent of consumption for the U.S., 14 percent for Japan, and 38 percent for Denmark. These are fantasy calculations - even ideally free trade is not costless trade - but they give useful upper bounds for the magnitude of gains we will be discussing in the rest of the paper.

These examples make clear that the parameters determining trade volume are informative about the welfare effects of tariffs. To see this, notice that trade volume given by (7.10) or (7.13) is a function of $(1-\alpha) / \beta$, which is the same expression appearing in the welfare gains (7.16). Also observe that trade volume in (7.13) as well as gains of trade in (7.16) are increasing functions of $\theta$.

Next we return to the case of positive transportation costs and tariffs, retaining symmetry. The properties of the volume and welfare gain functions defined in (7.13), and (7.14)-(7.15) are illustrated in Figures 7.1 through 7.4. In all cases, we used the values $\alpha=0.75, \beta=0.5$, and $\kappa=.75$. In the figures, the values of $\theta$ and the tariff parameter $\omega$ are varied, as shown.

Figure 7.1 shows the gains of eliminating a tariff corresponding to $\omega=.9$ for the same three values of $\theta$. Of course, the gains from eliminating a 10 percent tariff are far smaller than the gains (7.16) of moving from autarchy. Notice too that the gains in Figure 7.1 are not always decreasing in the the size of the country: This is due to the effect of the revenue from the tariff. As the formula (7.15) makes clear, 
there are two effects of eliminating a tariff (setting $\omega=1$ ). One is to reduce the price of the final, non-tradeable consumption good (that is, to increase $p / p_{0}$ ). The other is that tariff revenues are lost. These effects have opposing effects on welfare, and are stronger if $n$ is large (i.e. if countries are small). The first effect must dominate eliminating the tariff must be welfare improving-but the welfare gain need not decrease monotonically in $n$. We have computed the gains from eliminating a tariff for different $\omega$ values (not shown in Figure 7.1). Holding $\theta$ fixed at 0.15 , the difference in the welfare gains from eliminating a 30 percent versus a 20 percent tariff is smaller than the difference between eliminating a 40 percent versus a 30 percent tariff. For countries that are 5 percent of world GDP or smaller, the gains from eliminating a 30 percent tariffs are about 6 percent.

Figure 7.2 plots of the relation between the volume of trade, (7.13), measured as the ratio of import value to GDP, and the size of the economy. The volume of trade is decreasing in size, and is bounded above by the ratio of $(1-\alpha)$ to $(1-(1-\beta) \omega)$, which equals 0.45 for our benchmark parameter values and $\omega=0.9$. Small economies have trade volumes that nearly attain the bound. We have also experimented varying the value of $\omega$ between 0.7 and 1 (not shown in Figure 7.2). The effects of variation in $\omega$ are large for economies of all sizes: for an economy that is 5 percent of world GDP, trade volume increases from 10 percent to 27 percent, as tariffs are decreased from 30 percent to 10 percent.

Figure 7.1 - 7.2 refer to symmetric world economies, where all economies have the same size and technology levels. These are not cross-sections. The scatter of points in Figure 7.2 are GDPs, $Y_{i}$, and Import to GDP ratios, $V_{i}$, for 60 large countries: columns (1) and (2) in Table 2. These data are a cross-section. But the continuous curve on the picture is calculated for a symmetric world, with a $10 \%$ tariff $(\omega=0.9)$ just as in Figures 7.3 and 7.4, except that the $x$-axis is transformed to logs so that one can see the observed pairs for small countries. 
The data and all of the parameter values used to compute the theoretical curve in Figure 7.2 have all been discussed in Section 6. No adjustments have been made to fit the curve to the data. The theoretical curve reproduces the negative relation between trade volume and size in the data, but implies a higher average trade volume than the average implied by the data.

In a world with very different national policies toward trade one would not expect equal trade volumes at each GDP level, even if the assumptions underlying the construction of Figure 7.2 were correct: The points should not lie on the theoretical curve. If the theory were accurate, the rich economies with similar and more or less free trade - roughly, the OECD - should be near the curve, and the protectionist economies should fall below it by varying amounts.

There are also four striking outliers in the figure: Hong Kong, Singapore, Malaysia, and Belgium, with trade volumes much higher than others', and much higher than our theoretical upper bound. It is a characteristic of port cities that a high volume of goods passes through, counted as imports when they enter and exports when they leave. Countries in which such ports are important would appear as "low $\beta$ " countries in our parameterization, so it is possible that relaxing the assumption that $\beta$ is uniform across economies would yield a better fit of the volume-size curves in Figures 7.5 and 8.2 , below.

There is some evidence supporting this interpretation of the outliers in Figure 7.2 as low- $\beta$ port cities. The UN Statistics Division (Commodity Trade Statistics Database: COMTRADE) collects data on re-exports of goods - exports of goods that have been imported with no local value added-for 50 countries, 10 of which are in our 60 country data set. Of the four outlying high-volume countries in Figure 7.2, only Hong Kong has re-export data. Hong Kong reports that goods re-exports averaged about $85 \%$ of total goods exports during 1994-99. Since goods exports were about $86 \%$ of total exports, removing re-exports from total exports would lead to 
a reduction in the estimated trade volume in Hong Kong from 1.4 to $1.4 \times(.14+$ $.86 \times .15)=.38$, or to about the level of the theoretical curve in Figure 7.2. For the other 50 countries in the COMTRADE data set, re-exports are less than $10 \%$ of goods exports, and for most countries they are less than one percent of the total.

\section{INSERT FIGURES $7.1-7.2$}

\section{Volume of Trade}

The algorithm described in Section 5 lets us replace the theoretical curve in Figure 7.2, based on an assumption of symmetry, with the volume predictions of the general theory, calibrated to fit the actual distribution of economies by size. In addition, the general theory lets us incorporate other kinds of international differences - for example, differences in tariff policies - into the trade volume predictions. We do this in this section, in two ways.

Once the assumption of identical countries is dropped there is no reason for equilibrium wages to be equal, and if they are not, observed GDPs $Y$ cannot be taken as direct observations on labor-capital endowments $L$. Even without tariff distortions, $Y_{i}$ will be the product $w_{i} L_{i}$, and neither $w$ nor $L$ can be directly inferred from observations on $Y$. What can be done about this depends on what other data are used. We discuss several possibilities in the next three sections.

The simplest calibration method uses the theory to infer $w$ and $L$ from the data on $Y$ only. To do this, it seems a natural starting point to think of the parameter $\lambda_{i}$ in any country as proportional to that country's effective labor endowment $L_{i}$. That is, we assume that if country 1 has twice the labor endowment of country 2, that country will also have twice as many "draws" from the distribution of productivities. With exponentially distributed productivities, this means $\lambda_{1}=2 \lambda_{2}$, and in general, that the vector $\lambda$ is proportional to the endowment vector $L$. This assumption of 
uniform ratios $\lambda_{i} / L_{i}$ surely has more appeal than assuming uniform levels $\lambda_{i}$. In the latter case, there would be enormous diseconomies of size: Denmark would be the low cost producer of as many goods as the United States is, but with its much smaller workforce, Danish wage rates would be bid up to much higher levels than wages in the U.S. ${ }^{11}$ Of course, these are not the only possibilities. The assumption $\lambda=k L$ is at best a kind of steady state or very long run hypothesis, in the spirit of Kremer's (1993) idea that the stock of useful ideas should be proportional to the number of people.

Under this assumption, the equilibrium condition

$$
Z(w, L, \lambda)=0
$$

written so as to emphasize the dependence of the excess demand system $Z$ on $L$ and $\lambda$, is specialized to $Z(w, L, k L)=0$. The choice of the constant $k$ is just a matter of the units chosen for tradeables and labor input. We set it equal to one:

$$
Z(w, L, L)=0
$$

A second set of equations in the variables $w$ and $L$ is given by the GDP-equals-national income conditions

$$
L \cdot \varepsilon(w, L)=Y
$$

where $\varepsilon_{i}(w, \lambda)$ is $w_{i}$ adjusted for indirect taxes using the function of the equilibrium wage vector defined in equation (7.2):

$$
\varepsilon_{i}(w, \lambda)=w_{i}\left[1+\frac{\left(1-s_{f_{i}}(w, \lambda)\right)\left(1-F_{i}(w, \lambda)\right)}{\beta F_{i}(w, \lambda)}\right] .
$$

\footnotetext{
${ }^{11}$ See the costless trade formula $(7.5)$, for example. Note that although the hypothesis $\lambda=k L$ avoids an unrealistic diseconomy of scale, it leaves in place an unrealistic scale economy. In the theory, transportation costs within an economy, no matter how large, are taken to be zero. Insofar as the parameters $\kappa_{i j}$ measure the resources used in moving goods over space, this is a deficiency that can only be fixed by introducing some actual geography.
} 
(Notice that without tariffs, $\omega_{i}=1$ and $\varepsilon_{i}(w, \lambda)=w_{i}$.) We view (8.2) and (8.3) as $2 n$ equations in the pair $(w, L)$, given the data $Y$.

We describe the algorithm used to solve (8.2)-(8.3). Define $w^{*}(\lambda, L)$ to be the function that solves (8.1). Its values can be calculated using the algorithm described in Section 5. Define $\varphi$ by

$$
\varphi_{i}(L)=\frac{Y_{i}}{\varepsilon_{i}\left(w^{*}(L, L), L\right)} / \sum_{j=1}^{n} \frac{Y_{j}}{\varepsilon_{j}\left(w^{*}(L, L), L\right)} .
$$

Then $\varphi$ maps the $n$-dimensional simplex $\Delta_{n}$ into itself, and if $L$ is a fixed point of $\varphi$, the pair $\left(w^{*}(L, L), L\right)$ satisfies (8.2)-(8.3). We located a fixed point by iterating using (8.5), applying the algorithm from Section 5 to compute $w^{*}$ at each iteration, from an initial guess for $L$. In practice, this algorithm always converged to a fixed point. ${ }^{12}$

Figure 8.1 displays the equilibrium wages calculated in this way as a function of size (GDP share). The benchmark parameters used in Figures 7.1-7.2 were used, and the same range of $\theta$ values. The equilibrium wages are increasing with size, reflecting the scale economy in transportation enjoyed by larger economies. Since the technology level $\lambda$ is assumed proportional to size $L$ in the construction of the figure, it cannot provide a second source of wage variation.

Given equilibrium wages and endowments computed in this way, the analogues to Figures 7.1-7.2 are readily constructed. We were surprised to find that the new figures constructed in this way were very similar to the figures based on the assumption of equal size countries and wage equality, even though these two sets of assumptions seem very different.

This finding is illustrated in Figure 8.2. This figure is the exact analogue to Figure 7.2, except that the very high volume countries have been left off so as to

\footnotetext{
${ }^{12}$ Indeed, under the assumptions of Theorem 3 it can be shown that $\varphi: \operatorname{int}\left(\Delta_{n}\right) \rightarrow A \subset \operatorname{int}\left(\Delta_{n}\right)$, where $A$ is closed and convex, and that $\varphi$ is continuous, so that the existence of a fixed point follows from Brouwer's theorem.
} 
get higher resolution on the others. The volume and GDP data used in both figures are the same. The theoretical curve plotted in Figure 7.2, based on a symmetric model with identical countries and uniform wages, is reproduced on Figure 8.2, as is a new second curve, constructed by solving the general equilibrium system with endowments $L$ calibrated in the way we have just described. Despite the completely different computational methods used to construct them the two curves are very similar, except for the largest economies - Japan and the U.S. - where the symmetric model predicts a smaller volume than the more realistic one does. This is due to the effects of size on wages in the calibrated economy, shown on Figure 8.1. The implication we draw from the similarity of the two curves is that even though an economy's size relative to the world economy matters for the determination of trade volume, the way the rest of the world is configured matters very little.

\section{INSERT FIGURES $8.1-8.2$}

Neither of these curves is a particularly good fit: They pick up the effects of size on trade volume, and nothing else. Some other factors were remarked on in our discussion of Figure 7.2, and other possible influences will occur to anyone. Here we examine the possible effects of tariff policies, under the assumption-also used in Sections 5 and 7 - that each country $i$ imposes a uniform tariff factor $\omega_{i}$ on all countries $j$.

We introduce tariffs simply by repeating the simulation (8.2)-(8.3) with a uniform tariff factor of $\omega=0.9$ replaced by the vector $\Omega=\left(\Omega_{1}, \ldots, \Omega_{n}\right)$ of observed tariff factors, obtained from the tariff rates from column (4) of Table 2, interpreting $\Omega_{i}$ as the uniform tariff factor that country $i$ imposes on all imports. Results are shown on Figure 8.3, based on the same GDP and volume data as Figures 7.2 and 8.2. The o's are the data, the continuous curve is obtained from the calibrated model with a uniform tariff $\omega=0.9$. The asterisks are predictions from the calibrated model using 
the tariff factors $\Omega$ implied by Table 2 , column (4).

\section{INSERT FIGURE 8.3}

As a basis for comparison, we ran a regression of volume on GDP and tariffs levels for the 60 countries. The results were

$$
\log \left(\hat{V}_{i}\right)=a-(0.23) \log \left(Y_{i}\right)-(0.029)(100)\left(1-\Omega_{i}\right) .
$$

The associated $R^{2}$ was $.34 .^{13}$ The same statistic but with the estimates $\hat{V}_{i}$ of $V_{i}$ calculated from the theory (the x's on Figure 8.3) was also $R^{2}=(.58)^{2}=.34$. With the uniform tariff imposed, the comparable statistic was $R^{2}=(.45)^{2}=.20$. The slope parameters in (8.4) are freely chosen to fit the data. The effect of tariffs derived from the calibrated model was not selected in any way to improve the fit, and no actual tariff data (beyond average levels) was used in the calibration. Yet the tariffs have exactly the same (considerable) ability to improve the fit when constrained to work through our theory as with a freely chosen regression coefficient.

We also experimented with making $\kappa_{i j}$ a function of the distance between countries, and by taking into account the free trade agreements between countries in our data set. In both cases the simulated trade volumes became more correlated with the trade volume from the data, but the changes were small.

To model the effect on distance on transportation cost we let $d_{i j}$ be the distance between countries $i$ and $j$, measured in linear miles between the capitals of the two countries, normalized so that the average distance equals 1 . We let $\kappa_{i j}=$ $\kappa \exp \left(-\delta_{0}\left(d_{i j}-1\right)\right)$, so that $\delta_{0}$ has the interpretation of the elasticity of transportation cost with respect to distance. Using $\delta_{0}=0.05$, a number consistent with the empirical literature, we found that the correlation between the $(\log )$ model trade volume and the $(\log )$ trade volume in the data is 0.61 .

\footnotetext{
${ }^{13}$ We obtained only slightly different estimates when the four countries with trade volumes exceeding 0.75 were excluded from the regressions.
} 
To model the effect of the free trade agreements we let $\omega_{i j}=1$ for any two countries with a free-trade agreement, and otherwise used the tariffs described in Table 2. We considered the European Union, NAFTA, CEFTA and Mercosur. In this case we found that the correlation between the (log) model trade volume and the $(\log )$ trade volume in the data was 0.60 .

\section{Gains from Trade}

In Section 7 we studied the gains from trade using the autarchy versus costless trade example and hypothetical tariff reductions in the context of a symmetric world economy. In this section, we incorporate differences among countries in a more realistic way, using the general version of the theory calibrated to the actual world GDP distribution and the measured tariff factors $\Omega$ used in Section 8.

Results of a specific, world-wide tariff reduction are described below and displayed in figure 9.2. But before turning to these results, it will be helpful to study the effects of unilateral tariff changes in a small economy, or to calculate the "bestresponse function" for a small economy, taking the tariff policies of rest of the world as given. Studying this problem will help us to interpret the results of a uniform, multilateral tariff changes.

We focus on the case of economy 1 , say. We use the notation $L_{-1}=\left(L_{2}, L_{3}, \ldots L_{n}\right)$ and $\lambda_{-1}=\left(\lambda_{2}, \lambda_{3}, \ldots, \lambda_{n}\right)$ to denote the parameters corresponding to countries other than 1 , and similarly with $w_{-1}, c_{-1}$, and $p_{m-1}$. Assume that country 1 applies a uniform tariff $\omega$ to all its imports, and assume that all other countries apply a common tariff $\widehat{\omega}$ to country 1's exports. Our interest is in analyzing the behavior of country 1's welfare (final goods consumption) $c_{1}$ as a function of the pair $(\omega, \widehat{\omega})$.

To make precise the idea that country 1 is small, consider a sequence of world economies $\left\{L^{r}, \lambda^{r}\right\}$ with $\left(L^{r}, \lambda^{r}\right) \rightarrow(L, \lambda)$, and with $\lambda_{1}^{r} / L_{1}^{r}=k>0$ along the sequence. Let $\left\{w^{r}, c^{r}, p_{m}^{r}\right\}$ denote the corresponding sequence of equilibrium values, 
and let $\left(w, c, p_{m}\right)$ be the corresponding equilibrium values of the limiting economy. In Appendix $\mathrm{C}$ we establish that as $L_{1}^{r} \rightarrow 0$, the limiting behavior $\left(w_{-1}, c_{-1}, p_{m-1}\right)$ of the other $n-1$ economies is equal to the equilibrium of a world economy with $n-1$ countries and endowments $\left(L_{-1}, \lambda_{-1}\right)$, and that the limiting behavior of economy $1,\left(w_{1}, c_{1}, p_{m 1}\right)$, is given by

$$
\begin{aligned}
& w_{1}=\left[\frac{\alpha+(\beta-\alpha) \omega}{\omega^{1-(1-\beta) / \theta}} k\right]^{\theta /(\theta+\beta)} \widehat{\omega}^{(1+\theta) /(\theta+\beta)} \hat{w}_{1}, \\
c_{1}= & \omega^{(1-\alpha) /(\theta+\beta)}[1+(\beta-1) \omega] \\
& \times[\alpha+(\beta-\alpha) \omega]^{-(\alpha \theta+\beta) /(\theta+\beta)} \widehat{\omega}^{(1-\alpha)(1+\theta) /(\theta+\beta)} k^{\frac{(1-\alpha) \theta}{\theta+\beta}} \hat{c}_{1},
\end{aligned}
$$

and

$$
p_{m 1}=\hat{p}_{m 1} / \omega_{1}
$$

where the numbers $\hat{p}_{m 1}, \hat{w}_{1}$ and $\hat{c}_{1}$ do not depend on $\omega, \widehat{\omega}$ and $k$.

The expression (9.2) can then be used to calculate the optimal tariff: the level of $\omega$ that maximizes utility $c_{1}$ for country 1 . One can show, provided that $\beta<\alpha$, that there is a unique $\omega^{*}$ that maximizes $c_{1}$ and that the optimal tariff is strictly positive (that $\omega^{*} \in(0,1)$ ) and increasing in $\theta$. This result is quite intuitive. For small $\theta$ values, there are small differences across countries, and hence a given increase in tariffs produces a large decrease in the demands for the products of country 1. Consequently, the optimal tariff is decreasing in $\theta$. Figure 9.1, based on (9.2), illustrates the way utility $c_{1}$ varies with $\omega$ for different $\theta$ values. The vertical axis in the figure is $\log \left(c_{1}(\omega)\right)-\log \left(c_{1}(1)\right)$.

Should we be surprised at this persistence of market power as the economy becomes vanishingly small? Equation (9.3) states that as a buyer of tradeable goods the limit economy 1 is a price-taker. The set of tradeables it produces for home use has zero measure zero and it has no effect on the pre-tax price $\hat{p}_{m 1}$ of the tradeables aggregate. But under the Eaton-Kortum technology, any economy, no matter how 
small, has some goods which it is extremely efficient at producing, and even a small country can serve a large part of the world market for these particular goods. In our case, this market power cannot be exploited by individual sellers, because others in the same economy have free access to the efficient, constant returns technology. But as Figure 9.1 illustrates, it can be exploited by the government. Since we do not permit export duties, the way to restrict supply of these goods is through import tariffs. $^{14}$

\section{INSERT FIGURE 9.1}

It follows from these observations that a Nash equilibrium of a world-wide tariff game involving many small countries would involve strictly positive tariff levels for every country. We did not compute such an equilibrium. Instead, we calculated the analogue to the equilibrium shown in Figure 8.3 that results when the observed tariff factors $\Omega$ are replaced with the free-trade factors $(1,1, \ldots, 1)$. We then calculated the percentage increase in consumption that each country would receive under this elimination of tariffs. These gains are reported in Column (5) of Table 2. ${ }^{15}$ They are shown in Figure 9.2, plotted against each country's initial tariff rate, $\left(1-\Omega_{i}\right) \times 100$.

\footnotetext{
${ }^{14}$ A similar point is made in Helpman and Krugman (1989) and Gros (1987), in a context of imperfect competition. This analysis of the optimal tariff applies only for the small open economy case, but we have numerically verified for our calibrated economy that the calculations in Figure 9.1 are an excellent approximation for all but the largest economies. Compare to the Eaton and Kortum (2002, p. 1774) finding that if the U.S. were to reduce its tariffs on manufacturing goods unilaterally, it would suffer a welfare loss of about .0005\%.

${ }^{15}$ The overall magnitude of these estimates is within the rather wide range of estimates of static gains from tariff elimination that other economists have obtained. For example, Anderson (2004, Table 1) reports estimates of the gains from a hypothetical "full global liberalization" carried out in 2005 that range from $\$ 254$ to $\$ 2080$ b.(1995 dollars). Using an estimate of 2005 world GDP in 1995 dollars of $\$ 32000 \mathrm{~b}$. (our calculation) the implied range in percent is 0.8 to 6.5 . Most studies are nearer the lower end of this range. Our estimates are also similar to those reported by Eaton and Kortum (2002) for the mobile labor version of their model.
} 
Figure 9.3 reports the results of the same calculation, with the welfare gains plotted against size to facilitate comparison with Figure 7.1. ${ }^{16}$

\section{INSERT FIGURES 9.2 AND 9.3}

One can see the optimal tariff structure in Figure 9.1 reflected in the U-shaped pattern of gains from trade shown in Figure 9.2. The figure shows the effect of a tariff reform beginning from a situation in which tariffs vary realistically cross-sectionally and ending with all tariffs at zero. In the post-reform situation, every country would like to have its tariff at the best response to a world of zero tariffs. Countries with initial tariffs near this level lose the most from moving their own tariffs to zero, though they still gain from others' tariff reductions. Countries with very high initial tariffs gain from a reduction to the optimal tariff, but then lose some of these gains back as they continue toward zero. Countries with very low initial tariffs were never at their optimal tariff, so they only gain from others' reductions. From Figure 9.3, we can see two features already present in the symmetric example of Figure 7.1: first, for small countries with tariffs near $10 \%$ both figures give similar estimates of the welfare gains and, second, that the gains from trade are larger for smaller countries. Using the averages presented in Table 2, the world wide cost of the current level of import tariffs is $0.5 \%$ of world GDP and $31 \%$ of world tariff revenues.

\section{Sources of Income Differences}

As equations (7.7)-(7.9) of the costless trade example suggest, cross-section observations on the relative prices of tradeables and non-tradeables can be used to identify the vectors $L$ and $\lambda$ separately, in which case the proportionality assumption

\footnotetext{
${ }^{16}$ Incorporating distance into the transportation cost and incorporating the main free trade aggreements in the modeling of $\left[\omega_{i j}\right]$ as explained in section 8 have very small effects on patterns for the estimated welfare effects of a world trade liberalization.
} 
$\lambda=k L$ can be dropped. We base our final simulation on this idea.

In the general case, equation (2.12) implies that equilibrium wages and prices satisfy

$$
\frac{p_{i}}{p_{m i}}=\alpha^{-\alpha}(1-\alpha)^{-1+\alpha}\left(\frac{w_{i}}{p_{m i}(w, \lambda)}\right)^{\alpha}
$$

for all $i$, where the notation emphasizes that the right side can be computed as a function of $w$ and $\lambda$. Write $\psi(w, \lambda)$ for the $n$-vector of right side values, and view the relative prices on the left as the theoretical counterparts to the observed relative prices $P_{i}$ in column (3) of Table 2 . Then we can obtain estimates of $w, L$, and $\lambda$ by solving

$$
\begin{aligned}
& Z(w, L, \lambda)=0, \\
& L \cdot \varepsilon(w, \lambda)=Y,
\end{aligned}
$$

and

$$
\psi(w, \lambda)=P,
$$

where $\varepsilon$ is defined implicitly in (7.2). The system (10.1)-(10.3) consists of $3 n$ equations to be solved for the $3 n$ unknowns $w, L$, and $\lambda$. To solve this system, we used an algorithm that parallels the one described in Section 8.

The asterisks in Figure 10.1 are the equilibrium wages implied by this calculation, plotted against the log of GDPs. The circles in the figure are the equilibrium wages from the analogous calculation described in Section 8, in which the ratios $\lambda_{i} / L_{i}$ are constrained to equal a common value. (Neither reported calculation uses tariff data, but we have carried out versions that do so: The figure is not much affected.) One can see that constraining $\lambda_{i} / L_{i}$ to be constant suppresses most of the cross-country variability in equilibrium wages, relative the case where variations in $\lambda_{i}$ and $L_{i}$ are permitted to exercise independent influences. The two log standard deviations in the upper right of the figure quantify this difference.

\section{INSERT FIGURE 10.1}


In these calculations relative price data were used to identify these effects separately. Cross-country data on real wages of labor at equal skill levels could have been used for this purpose, too, or some combination of the two. One can see from Table 2 that the observed relative prices $P_{i}$ are strongly correlated with per capita GDPs. This is also true of the equilibrium wage rates $w_{i}$ obtained by solving (10.1)-(10.3), and we believe it would be true of measured wages as well (though controlling for international skill differences would not be easy, and we have not carried this latter comparison out).

Interpreting the simulation results in this section and in Section 8 entails a kind of cross-country accounting of the sources of income differences, similar to growth accounting based on time-series data. In Sections 8 and 9 , where $\lambda_{i}$ is constrained to be proportional to $L_{i}$, individuals in all countries are viewed as drawing productionrelated ideas from a common distribution. Productivity differences for individual goods are just a matter of chance and these differences average out over the whole economy. Differences in overall production are almost all due to differences in resource endowments: population and human and physical capital per person.

Of course, the focus of Sections 8 and 9 was on the determination of trade flows and the consequences of policy changes that affect these flows, and we think we have made some progress on these questions. It is reassuring that the simulations of this section, with $\lambda_{i} / L_{i}$ left free, give very similar answers on the volume of, and gains from, trade as the constrained simulations do.

\section{Conclusion}

We think of this paper as a kind of trial run of a particular version of the Eaton and Kortum trade theory. As we formulated the theory, the problem of solving for equilibrium prices and quantities can be reduced to solving for the vector of equilibrium wages in the $n$ countries that comprise the world economy, very much 
along the lines of Wilson's (1980) analysis. We have shown that such an equilibrium exists under reasonable conditions and that under somewhat tighter assumptions it will be unique. We have proposed and tested an algorithm that is essentially a tatonnement process for calculating equilibria. We have discovered that "toy versions" of the theory can provide surprisingly accurate approximations to predictions about wages, trade volumes and gains from trade, so pencil-and-paper calculations can be used to provide inexpensive checks on quantitative conjectures and to help interpret simulation results.

For the most part, objects in the theory match up naturally to counterparts in the national income and product accounts, input-output accounts, and standard trade statistics. This makes much of the calibration easy to carry out, lets us focus attention sharply on small regions of the theory's parameter space, and facilitates interpretation of simulation results. These features are essential to successful quantitative economics.

The calibrated model accounts fairly well for the overall volume of world trade in the year 2000, and for the way volume varies cross-sectionally with an economy's size and tariff levels. With its assumption of continuous trade balance, the theory is obviously not designed to interpret short term fluctuations. We have not tested the theory's ability to account for trends in trade volumes (as studied, for example, in Yi (2003)) nor have we responded to Kehoe's (2002) challenge to provide a satisfactory account of the effects of NAFTA or other important trade agreements. These issues are high on our agenda, as they are on every quantitative international economist's.

We have kept the analysis in this paper on a strictly static basis, in order to keep complications within bounds and to understand better the connections with other trade theories. The cost of this decision was to leave the model's many connections to growth theory and public finance unexplored. A more satisfactory treatment of physical capital is needed, in which the dynamics of capital accumulation can be examined as well as the contributions of capital to current production. Capital goods 
play a large role in trade, so it is natural to conjecture that tariff and other barriers have large effects on the return to investment and hence on capital accumulation and growth. We are currently exploring this topic. Another natural direction, already examined by Eaton and Kortum (1999), will be to introduce technology diffusion by introducing a law of motion for the parameters $\lambda$. Perhaps in some combination such extensions can help us to discover the long-sought theoretical link between trade and growth. 


\section{REFERENCES}

[1] Anderson, James E., and Eric van Wincoop. 2004. "Trade Costs." Journal of Economic Literature, 42: 691- 751.

[2] Anderson, Kym. 2004. "Subsidies and Trade Barriers." Copenhagen Consensus Challenge Paper.

[3] Bela Balassa. 1964. "The Purchasing-Power Parity Doctrine: A Reappraisal." Journal of Political Economy, 72: 584-596.

[4] Baxter, Marianne. 1992. "Fiscal Policy, Specialization, and Trade in the Two-Sector Model: The Return of Ricardo?" Journal of Political Economy. 100: 713-744.

[5] Broda, Christian, and David E. Weinstein, 2005. "Globalization and the Gains from Variety". Manuscript.

[6] Dollar, David, and Aart Kraay. 2004. "Trade, Growth, and Poverty." Economic Journal, 114: F22-F49.

[7] Dornbusch, Rudiger, Stanley Fischer, and Paul A. Samuelson. 1977. "Comparative Advantage, Trade, and Payments in a Ricardian Model with a Continuum of Goods." American Economic Review. 67: 823-839.

[8] Eaton, Jonathan, and Samuel Kortum. 2002. "Technology, Geography, and Trade." Econometrica. 70: 1741-1779.

[9] Eaton, Jonathan, and Samuel Kortum. 1999. "International Technology Diffusion: Theory and Measurement." International Economic Review. 40: 537-570.

[10] Ethier, Wilfred J. 1979. "Internationally Decreasing Costs and World Trade." Journal of International Economics. 9: 1-24. 
[11] Ethier, Wilfred J. 1982. "National and International Returns to Scale in the Modern Theory of International Trade." American Economic Review. 72: 389-405.

[12] Gros, Daniel. 1987. "A Note on the Optimal Tariff, Retaliation and the Welfare Loss from Tariff Wars in a Framework with Intra-Industry Trade." Journal of International Economics. 23: 357-367.

[13] Helpman, Elhanan. 1981. "International Trade in the Presence of Product Differentiation, Economies of Scale and Monopolistic Competition." Journal of International Economics. 11: 305-340.

[14] Helpman, Elhanan, and Paul R. Krugman, 1985. Market Structure and Foreign Trade. Cambridge: MIT Press.

[15] Helpman, Elhanan, and Paul R. Krugman, 1989. Trade Policy and Market Structure. Cambridge: MIT Press.

[16] Hummels, David. 1999. "Have International Transportation Costs Declined?" University of Chicago working paper.

[17] Kehoe, Timothy J. 2002. "An Evaluation of the Performance of Applied General Equilibrium Models of the Impact of NAFTA." Federal Reserve Bank of Minneapolis Research Department Staff Report.

[18] Michael Kremer. 1993. "Population Growth and Technological Change: One Million B.C. to 1990." Quarterly Journal of Economics, 108: 681-716.

[19] Krugman, Paul. 1979. "Increasing Returns, Monopolistic Competition, and International Trade." Journal of International Economics. 9: 469-480.

[20] Andreu Mas-Collel, Michael D. Whinston, and Jerry R. Green. Microeconomic Theory. 1995. New York: Oxford University Press. 
[21] Paul A. Samuelson. 1964. "Theoretical Notes on Trade Problems." Review of Economics and Statistics, 46: 145-154.

[22] Syverson, Chad. 2003. "Market Structure and Productivity: A Concrete Example." University of Chicago working paper.

[23] Wilson, Charles A. 1980. "On the General Structure of Ricardian Models with a Continuum of Goods: Applications to Growth, Tariff Theory, and Technical Change." Econometrica. 48: 1675-1702.

[24] Yi, Kei Mu. 2003. "Can Vertical Specialization Explain the Growth of World Trade." Journal of Political Economy. 111: 52-102.

\section{Appendix A: Proofs of Theorem 2, (iv) and (v).}

Proof of part (iv). The lower bound on $Z_{i}(w)$ is implied by

$$
\begin{aligned}
Z_{i}(w) & =\frac{1}{w_{i}}\left[\sum_{j=1}^{n} L_{j} w_{j}\left(1-s_{j}\right) \frac{1}{F_{j}} D_{j i} \omega_{j i}-L_{i} w_{i}\left(1-s_{f_{i}}\right)\right] \\
& \geq-L_{i}\left(1-s_{f_{i}}\right) \geq-L_{i} .
\end{aligned}
$$

Proof of part (v). Suppose that $\left\{w^{m}\right\}$ is a sequence in $\mathbf{R}_{++}^{n}$, that $w^{m} \rightarrow w^{0} \neq 0$, and that $w_{i}^{0}=0$ for some $i$. We need to verify that (4.9) holds for this sequence. For any $w \in \mathbf{R}_{++}^{n}$, we have

$$
\begin{aligned}
\max _{k} Z_{k}(w) & =\max _{k}\left[\sum_{j=1}^{n} L_{j} \frac{w_{j}}{w_{k}}\left(1-s_{j}\right) \frac{1}{F_{j}} D_{j k} \omega_{j k}-L_{k}\left(1-s_{k}\right)\right] \\
& \geq \max _{k} \sum_{j=1}^{n} L_{j} \frac{w_{j}}{w_{k}}\left(1-s_{j}\right) D_{j k} \omega_{j k}-\max _{k} L_{k} \\
& \geq \max _{k, j} L_{j} \frac{w_{j}}{w_{k}}\left(1-s_{j}\right) D_{j k} \omega_{j k}-\max _{k} L_{k} .
\end{aligned}
$$


By Assumption (A), $\omega_{j k} \geq \underline{\omega}$, implying in turn that the functions $F_{i}$ take values in $[\underline{\omega}, 1]$. Then (3.18) implies that the shares $1-s_{j}$ are uniformly bounded away from zero. Thus (4.9) will be proved if it can be shown that

$$
\max _{k, j} \frac{w_{j}^{m}}{w_{k}^{m}} D_{j k}\left(w^{m}\right) \rightarrow \infty
$$

for the wage sequence $\left\{w^{m}\right\}$. From (3.11) we have, for any $w$

$$
D_{j k}(w) \geq(A B)^{-1 / \theta}(\underline{\kappa \omega})^{1 / \theta} \lambda_{k}\left(\frac{p_{m k}}{w_{k}}\right)^{\beta / \theta}\left(\frac{p_{m j}}{p_{m k}}\right)^{1 / \theta} .
$$

Using (3.11) directly,

$$
\left(\frac{p_{m j}}{p_{m k}}\right)^{1 / \theta}=\left[\sum_{r=1}^{n}\left(\frac{w_{r}^{\beta} p_{m r}^{1-\beta}}{\kappa_{j r} \omega_{j r}}\right)^{-1 / \theta} \lambda_{r}\right]^{-1} \sum_{r=1}^{n}\left(\frac{w_{r}^{\beta} p_{m r}^{1-\beta}}{\kappa_{k r} \omega_{i r}}\right)^{-1 / \theta} \lambda_{r} \geq(\underline{\kappa \omega})^{1 / \theta} .
$$

Using the lower bound established in Theorem 1, (v), we have

$$
\left(\frac{p_{m k}}{w_{k}}\right)^{\beta / \theta} \geq w_{k}^{-\beta / \theta}(A B)^{1 / \theta}\left(\sum_{r=1}^{n} w_{r}^{-\beta / \theta} \lambda_{r}\right)^{-1} .
$$

It follows from (A.2)-(A.4) that

$$
\frac{w_{j}}{w_{k}} D_{j k}(w) \geq(\underline{\kappa \omega})^{2 / \theta} \lambda_{k}\left(\sum_{r=1}^{n}\left(\frac{w_{k}}{w_{r}}\right)^{\beta / \theta} \lambda_{r}\right)^{-1} \frac{w_{j}}{w_{k}}
$$

and therefore that for all $w$,

$$
\max _{k, j} \frac{w_{j}}{w_{k}} D_{j k}(w) \geq(\underline{\kappa \omega})^{2 / \theta}\left(\min _{k} \lambda_{k}\right)\left(\sum_{r=1}^{n} \lambda_{r}\right)^{-1} \frac{\max _{j} w_{j}}{\min _{k} w_{k}} .
$$

Since the $w^{m} \rightarrow w^{0} \neq 0$ with $w_{i}^{0}=0$ for some $i$

$$
\begin{aligned}
\max _{j} w_{j}^{m} & \rightarrow \max _{j} w_{j}^{0}>0, \quad \text { and } \\
\min _{k} w_{k}^{m} & \rightarrow \min _{k} w_{k}^{0}=0 .
\end{aligned}
$$

This verifies (A.1) and hence (4.9) and completes the proof of Theorem 2. 


\section{Appendix B: Proof of Theorem 3.}

We show that $Z$ has the gross substitute property (5.7):

$$
\frac{\partial Z_{i}(w)}{\partial w_{k}}>0 \quad \text { for all } i, k, \quad i \neq k, \quad \text { for all } w \in \mathbf{R}_{++.} \text {. }
$$

Before calculating the derivatives, note that $Z_{i}$ can be written as

$$
Z_{i}(w)=\frac{(1-\alpha) \beta}{w_{i}}\left[\sum_{j=1}^{n} \frac{L_{j} w_{j} D_{j i} \omega_{j}}{\alpha+(\beta-\alpha) F_{j}}-\frac{L_{i} w_{i} F_{i}}{\alpha+(\beta-\alpha) F_{i}}\right]
$$

using (3.18) to substitute for $s_{j}$ in (3.24) and using the fact that

$$
(1-\alpha) \beta F_{j}+\alpha\left[1-(1-\beta) F_{j}\right]=\alpha+(\beta-\alpha) F_{j}
$$

Thus we can write the derivatives in (5.7) as

$$
\begin{aligned}
\frac{\partial Z_{i}(w)}{\partial w_{k}}= & \frac{(1-\alpha) \beta}{w_{i}} \sum_{j=1, j \neq i, j \neq k}^{n} L_{j} w_{j} \omega_{j} \frac{\partial}{\partial w_{k}}\left(\frac{D_{j i}}{\alpha+(\beta-\alpha) F_{j}}\right) \\
& +\frac{(1-\alpha) \beta}{w_{i}} L_{k} \omega_{k} \frac{\partial}{\partial w_{k}}\left(\frac{w_{k} D_{k i}}{\alpha+(\beta-\alpha) F_{k}}\right) \\
& +(1-\alpha) \beta L_{i} \frac{\partial}{\partial w_{k}}\left(\frac{D_{i i}-F_{i}}{\alpha+(\beta-\alpha) F_{i}}\right) .
\end{aligned}
$$

In the following three steps we sign each of the three terms of this derivative.

- Step (ia): If (5.4) holds, then $\partial D_{j i} / \partial w_{k}>0$ for all $j \neq i$. To see this, notice that direct computation gives

$$
\frac{\partial D_{j i}}{\partial w_{k}}=\frac{D_{j i}}{w_{k}} \frac{1}{\theta}\left[\frac{\partial \tilde{p}_{m j}}{\partial \tilde{w}_{k}}-(1-\beta) \frac{\partial \tilde{p}_{m i}}{\partial \tilde{w}_{k}}\right] .
$$

Let $\hat{\xi}_{k} \equiv\left(\left(w_{k}^{\beta} p_{m k}^{1-\beta}\right)^{-1 / \theta} \lambda_{k}\right) / \sum_{r=1}^{n}\left(w_{r}^{\beta} p_{m r}^{1-\beta}\right)^{-1 / \theta} \lambda_{r}$, so that $\xi_{i k}, \underline{\xi}_{k}$, and $\bar{\xi}_{k}$ imply

$$
(\underline{\kappa \omega})^{1 / \theta} \hat{\xi}_{k} \leq \underline{\xi}_{k} \leq \xi_{i k} \leq \bar{\xi}_{k} \leq \frac{1}{(\underline{\kappa \omega})^{1 / \theta}} \hat{\xi}_{k}
$$


for all $i$. Then Theorem 1 (vi) implies

$$
\begin{aligned}
\frac{\partial D_{j i}}{\partial w_{k}} & \geq \frac{D_{j i}}{w_{k}} \frac{1}{\theta}\left[\underline{\xi}_{k}-(1-\beta) \bar{\xi}_{k}\right] \geq \frac{D_{j i}}{w_{k}} \frac{1}{\theta} \hat{\xi}_{k}\left[(\underline{\kappa \omega})^{1 / \theta}-\frac{(1-\beta)}{(\underline{\kappa \omega})^{1 / \theta}}\right] \\
& =\frac{D_{j i}}{w_{k}} \frac{1}{\theta(\underline{\kappa \omega})^{1 / \theta}} \hat{\xi}_{k}\left[(\underline{\kappa \omega})^{2 / \theta}-(1-\beta)\right]
\end{aligned}
$$

which is positive if (5.4) holds.

- Step (ib): If $\beta \leq \alpha$ then for $j \neq k, \partial\left(\alpha+(\beta-\alpha) F_{j}\right) / \partial w_{k} \leq 0$. To see this, notice that under the assumption of uniform tariffs

$$
F_{j}=\omega_{j}+\left(1-\omega_{j}\right) D_{j j}=\omega_{j}+\left(1-\omega_{j}\right)(A B)^{-1 / \theta}\left(\frac{p_{m j}}{w_{j}}\right)^{\beta / \theta} \lambda_{j} .
$$

Hence

$$
\frac{\partial}{\partial w_{k}}\left(\alpha+(\beta-\alpha) F_{j}\right)=(\beta-\alpha)\left(1-\omega_{j}\right) \frac{\partial D_{j j}}{\partial w_{k}}
$$

and for $j \neq k$

$$
\frac{\partial D_{j j}}{\partial w_{k}}=(\beta / \theta) \frac{D_{j j}}{p_{m j}} \frac{\partial p_{m j}}{\partial w_{k}}>0,
$$

by (iii) in Theorem 1 . Thus if (5.5) holds (if $\beta \leq \alpha$ ) then

$$
\frac{\partial}{\partial w_{k}}\left(\alpha+(\beta-\alpha) F_{j}\right)=(\beta-\alpha)\left(1-\omega_{j}\right)(\beta / \theta) \frac{D_{j j}}{p_{m j}} \frac{\partial p_{m j}}{\partial w_{k}} \leq 0 .
$$

Clearly, (ia) and (ib) imply that

$$
\sum_{j=1, j \neq i, j \neq k}^{n} L_{j} w_{j} \omega_{j} \frac{\partial}{\partial w_{k}}\left(\frac{D_{j i}}{\alpha+(\beta-\alpha) F_{j}}\right)>0 .
$$

- Step (ii): If (5.5) and (5.6) hold for $k \neq i, \partial\left(\frac{w_{k} D_{k i}}{\left[\alpha+(\beta-\alpha) F_{k}\right]}\right) / \partial w_{k}>0$. To see this notice that direct computation gives

$$
\begin{aligned}
& \frac{\partial}{\partial w_{k}}\left(\frac{w_{k} D_{k i}}{\alpha+(\beta-\alpha) F_{k}}\right) \\
= & \frac{\left(D_{k i}+w_{k} \partial D_{k i} / \partial w_{k}\right)\left(\alpha+(\beta-\alpha) F_{k}\right)-w_{k} D_{k i}(\beta-\alpha) \partial F_{k} / \partial w_{k}}{\left[\alpha+(\beta-\alpha) F_{k}\right]^{2}}
\end{aligned}
$$


In step (ia) we verify that (5.4) implies that $\partial D_{k i} / \partial w_{k} \geq 0$ so that it will suffice to show that

$$
\frac{D_{k i}\left(\alpha+(\beta-\alpha) F_{k}\right)-w_{k} D_{k i}(\beta-\alpha) \partial F_{k} / \partial w_{k}}{\left[\alpha+(\beta-\alpha) F_{k}\right]^{2}} \geq 0 .
$$

Using (B.1),

$$
\frac{\partial F_{k}}{\partial w_{k}}=\left(1-\omega_{k}\right) \frac{\partial D_{k k}}{\partial w_{k}}=\left(1-\omega_{k}\right) \frac{D_{k k}}{w_{k}} \frac{\beta}{\theta}\left[\frac{\partial \tilde{p}_{m k}}{\partial \tilde{w}_{k}}-1\right] \geq-\left(1-\omega_{k}\right) \frac{1}{w_{k}}(\beta / \theta)
$$

since $D_{k k} \leq 1$ and $\partial \tilde{p}_{m k} / \partial \tilde{w}_{k}>0$. Thus

$$
\begin{aligned}
\frac{\partial}{\partial w_{k}}\left(\frac{w_{k} D_{k i}}{\alpha+(\beta-\alpha) F_{k}}\right) & \geq D_{k i} \frac{\left(\alpha+(\beta-\alpha) F_{k}\right)+(\beta-\alpha)\left(1-\omega_{k}\right)(\beta / \theta)}{\left[\alpha+(\beta-\alpha) F_{k}\right]^{2}} \\
& =\frac{D_{k i}}{\left[\alpha+(\beta-\alpha) F_{k}\right]}\left[1-\frac{(\alpha-\beta)\left(1-\omega_{k}\right)(\beta / \theta)}{\left[\alpha+(\beta-\alpha) F_{k}\right]}\right]
\end{aligned}
$$

and since $F_{k} \in[\underline{\omega}, 1]$ and $\beta \leq \alpha$

$$
\begin{aligned}
\frac{\partial}{\partial w_{k}}\left(\frac{w_{k} D_{k i}}{\alpha+(\beta-\alpha) F_{k}}\right) & \geq \frac{D_{k i}}{\left[\alpha+(\beta-\alpha) F_{k}\right]}\left[1-\frac{(\alpha-\beta)\left(1-\omega_{k}\right)(\beta / \theta)}{\beta}\right] \\
& =\frac{D_{k i}}{\left[\alpha+(\beta-\alpha) F_{k}\right]}\left[1-\frac{(\alpha-\beta)\left(1-\omega_{k}\right)}{\theta}\right]
\end{aligned}
$$

and thus if if condition (5.6) holds the inequality in step ii) is verified.

- Step (iii) For $k \neq i, \partial\left(D_{i i}-F_{i} /\left[\alpha+(\beta-\alpha) F_{i}\right]\right) / \partial w_{k}>0$.To see this, use (B.1) so that

$$
\frac{D_{i i}-F_{i}}{\alpha+(\beta-\alpha) F_{i}}=\frac{-\omega_{i}\left(1-D_{i i}\right)}{\alpha+(\beta-\alpha)\left(\omega_{i}+\left(1-\omega_{i}\right) D_{i i}\right)} .
$$

Hence

$$
\frac{\partial}{\partial w_{k}}\left(\frac{D_{i i}-F_{i}}{\alpha+(\beta-\alpha) F_{i}}\right)=\frac{\partial}{\partial D_{i i}}\left(\frac{-\omega_{i}\left(1-D_{i i}\right)}{\alpha+(\beta-\alpha)\left(\omega_{i}+\left(1-\omega_{i}\right) D_{i i}\right)}\right) \frac{\partial D_{i i}}{\partial w_{k}}
$$

with $\partial D_{i i} / \partial w_{k}=(\beta / \theta)\left[D_{i i} / p_{m i} \partial p_{m i} / \partial w_{k}\right]>0$ and

$$
\begin{aligned}
& \frac{\partial}{\partial D_{i i}}\left(\frac{-\omega_{i}\left(1-D_{i i}\right)}{\alpha+(\beta-\alpha)\left(\omega_{i}+\left(1-\omega_{i}\right) D_{i i}\right)}\right) \\
& =\frac{\omega_{i} \beta}{\left[\alpha+(\beta-\alpha)\left(\omega_{i}+\left(1-\omega_{i}\right) D_{i i}\right)\right]^{2}}>0
\end{aligned}
$$


which establishes the inequality in step (iii).

This shows that $Z$ satisfies the gross substitute property, and hence that the equilibrium is unique.

\section{Appendix C: Behavior of the Limiting Economies}

We verify that as $L_{1}^{r} \rightarrow 0$, the limiting behavior $\left(w_{-1}, c_{-1}, p_{m-1}\right)$ of the other $n-1$ economies is equal to the equilibrium of a world economy with $n-1$ countries and endowments $\left(L_{-1}, \lambda_{-1}\right)$, and that the limiting behavior of economy $1,\left(w_{1}, c_{1}, p_{m 1}\right)$, satisfies (9.1)-(9.3). We proceed under the hypothesis that $w_{1} \in(0, \infty)$, which we verify later on. Then when $\lambda_{1}=k L_{1}=0,(3.11)$ implies

$$
p_{m i}=A B\left(\sum_{j=2}^{n}\left(\frac{w_{j}^{\beta} p_{m j}^{1-\beta}}{\kappa_{i j} \omega_{i j}}\right)^{-1 / \theta} \lambda_{j}\right)^{-\theta},
$$

for all $i$ and, using the assumption that country 1 imposes a uniform tariff $\omega$,

$$
p_{m 1}=\omega^{-1} A B\left(\sum_{j=2}^{n}\left(\frac{w_{j}^{\beta} p_{m j}^{1-\beta}}{\kappa_{1 j}}\right)^{-1 / \theta} \lambda_{j}\right)^{-\theta}=\omega^{-1} \hat{p}_{m 1} .
$$

The second equality defines $\hat{p}_{m 1}$ and verifies (9.3).

The fraction of country $j$ 's expenditures on tradeables produced by country 1 is

$$
D_{j 1}(w)=(A B)^{-1 / \theta}\left[\frac{p_{m j} \kappa_{j 1} \omega_{j}}{p_{m 1}^{1-\beta} w_{1}^{\beta}}\right]^{1 / \theta} \lambda_{1}=0 .
$$

As $L_{1}^{r} \rightarrow 0$, this fraction goes to zero for each $j, \lim _{r \rightarrow \infty} D_{j 1}\left(w^{r}\right)=0$. Inspection of the expression for $Z_{i}(w)$ then confirms that when $\lambda_{1}=k L_{1}=0$ the excess demand system $Z_{-1}(w) \equiv\left(Z_{2}(w), Z_{3}(w), \ldots Z_{n}(w)\right)=0$ does not depend on $w_{1}, \widehat{\omega}, \omega$. The continuity of $Z$ implies that $w_{-1}$ solving $Z_{-1}\left(w_{1},\left(w_{-1}\right)\right)=0$ is the desired limit.

The next step is to derive an expression for the limit for economy 1 . We take $w_{-1}$ as given in the previous step. For $L_{1}>0$, we have that $Z_{1}\left(w_{1}, w_{-1}\right)=0$ is equivalent to $Z_{1}\left(w_{1}, w_{-1}\right) / L_{1}=0$, so we analyze the latter expression. It can be shown, 
using the formulas (3.17) and (3.18) that for $L_{1}>0$, the ratio $Z_{1}\left(w_{1}, w_{-1}\right) / L_{1}=0$ is equivalent to

$$
\begin{aligned}
& \sum_{j=2}^{n} L_{j} \frac{w_{j}\left(1-s_{j}\right)}{F_{j}}(A B)^{-1 / \theta}\left(p_{m j} \kappa_{j 1}\right)^{1 / \theta} k\left(\frac{1}{p_{m 1}^{1-\beta} w_{1}^{\beta}}\right)^{1 / \theta} \hat{\omega}^{1+1 / \theta} \\
= & w_{1}^{1+\beta / \theta} \frac{(1-\alpha) \beta F_{1}}{\alpha+(\beta-\alpha) F_{1}}\left[1-\frac{1}{F_{1}}(A B)^{-1 / \theta}\left(\frac{p_{m 1}}{w_{1}}\right)^{\beta / \theta} L_{1}\right]
\end{aligned}
$$

As $\lambda_{1}=k L_{1} \rightarrow 0$, then $D_{11} \rightarrow 0$, and hence $F_{1}=D_{11}+\left(1-D_{11}\right) \omega \rightarrow \omega$. Thus, taking the limit as $L_{1} \rightarrow 0$ yields

$$
\begin{aligned}
& \sum_{j=2}^{n} L_{j} \frac{w_{j}\left(1-s_{j}\right)}{F_{j}}(A B)^{-1 / \theta}\left(p_{m j} \kappa_{j 1}\right)^{1 / \theta} k \hat{\omega}^{(1+\theta) / \theta} \\
= & w_{1}^{1+\beta / \theta} \frac{(1-\alpha) \beta \omega}{\alpha+(\beta-\alpha) \omega}\left(p_{m 1}\right)^{(1-\beta) / \theta} .
\end{aligned}
$$

Solving for $w_{1}$ yields $(9.1)$, where it can be seen that the factor $\hat{w}_{1}$ does not depend on $\omega, \widehat{\omega}$ and $k$.

Finally we turn to the calculation of $c_{1}$. From (7.2) we have that with uniform tariffs

$$
p_{1} c_{1} L_{1}=L_{1} w_{1}\left[1+\frac{(1-\alpha)\left(1-\omega_{1}\right)}{\alpha+(\beta-\alpha) F_{1}}\left(1-D_{11}\right)\right] \text {. }
$$

and since $D_{11} \rightarrow 0$ and $F_{1} \rightarrow \omega_{1}$ as $L_{1} \rightarrow 0$ then

$$
\lim _{L_{1} \rightarrow 0} p_{1} c_{1}=w_{1}\left[1+\frac{(1-\alpha)\left(1-\omega_{1}\right)}{\alpha+(\beta-\alpha) \omega_{1}}\right]=w_{1}\left[\frac{\beta \omega_{1}+\left(1-\omega_{1}\right)}{\alpha+(\beta-\alpha) \omega_{1}}\right] \text {. }
$$

Using the expression for $p_{1}$ in (2.12),

$$
c_{1}=\frac{1}{\alpha^{-\alpha}(1-\alpha)^{-1+\alpha}}\left(\frac{w_{1}}{p_{m 1}}\right)^{1-\alpha}\left[\frac{\beta \omega+(1-\omega)}{\alpha+(\beta-\alpha) \omega}\right] .
$$

Using the expression for $p_{m 1}$ in (9.3) and for $w_{1}$ in (9.1),

$$
\begin{aligned}
c_{1}= & \frac{1}{\alpha^{-\alpha}(1-\alpha)^{-1+\alpha}}\left(\frac{\omega}{\hat{p}_{m 1}}\right)^{1-\alpha}\left[\frac{\beta \omega+(1-\omega)}{\alpha+(\beta-\alpha) \omega}\right] \\
& \times\left(\frac{\alpha+(\beta-\alpha) \omega}{(1-\alpha) \beta \omega}\left(\frac{\omega}{\hat{p}_{m 1}}\right)^{(1-\beta) / \theta} G\left(w_{-1}\right) k \widehat{\omega}^{(1+\theta) / \theta}\right)^{\frac{(1-\alpha) \theta}{\theta+\beta}},
\end{aligned}
$$


where

$$
G\left(w_{-1}\right)=\left[\sum_{j=2}^{n} L_{j} \frac{w_{j}\left(1-s_{j}\right)}{F_{j}}(A B)^{-1 / \theta}\left(p_{m j} \kappa_{j 1}\right)^{1 / \theta}\right]^{\theta /(\theta+\beta)}
$$

Collecting terms involving $\omega, \widehat{\omega}$ and $k$ :

$$
c_{1}=k^{\frac{(1-\alpha) \theta}{\theta+\beta}} \omega^{\frac{1-\alpha}{\theta+\beta}}[1+(\beta-1) \omega][\alpha+(\beta-\alpha) \omega]^{-\frac{\alpha \theta+\beta}{\theta+\beta}} \widehat{\omega}^{\frac{(1-\alpha)(1+\theta)}{\theta+\beta}} \hat{c}_{1}
$$

where it can be seen that the factor $\hat{c}_{1}$ does not depend on $\omega, \widehat{\omega}$ or $k$.

$$
\hat{c}_{1}=\frac{\left(\hat{p}_{m 1}\right)^{-(1-\alpha)\left[\frac{1+\theta}{\theta+\beta}\right]}}{\alpha^{-\alpha}(1-\alpha)^{-1+\alpha}}\left(\frac{G\left(w_{-1}\right)}{(1-\alpha) \beta}\right)^{\frac{(1-\alpha) \theta}{\theta+\beta}}
$$

This completes the proof. 


\section{TABLE 2: DATA AND SIMULATION RESULTS}

\begin{tabular}{|c|c|c|c|c|c|c|c|}
\hline Country Name & $\begin{array}{c}\text { Size } \\
\text { GDP as \% of } \\
\text { World GDP } \\
Y_{\mathrm{i}}[1]\end{array}$ & $\begin{array}{c}\text { Trade Volume } \\
\text { Imports /GDP } \\
\qquad V_{i}[2]\end{array}$ & $\begin{array}{l}\text { Relative Price } \\
\text { Consumption / } \\
\text { Mach. \& Equipt } \\
\mathrm{P}_{\mathrm{i}}\end{array}$ & $\begin{array}{c}\text { Tariff (in \%) } \\
\text { Mean across } \\
\text { goods } \\
100 \times\left(1-\Omega_{\mathrm{i}}\right)[4]\end{array}$ & $\begin{array}{c}\text { Welfare Gain } \\
\text { of eliminating } \\
\text { tariffs, in percent }\end{array}$ & $\begin{array}{r}\text { Per Capita } \\
\text { PPP Adju } \\
\text { US }=1 \\
y_{i}\end{array}$ & $\begin{array}{l}\text { GDP } \\
\text { sted } \\
{[6]}\end{array}$ \\
\hline United States & 27.99 & 0.10 & 1.37 & 5.40 & 0.15 & & 1.00 \\
\hline Japan & 15.69 & 0.08 & 1.65 & 5.48 & 0.25 & & 0.83 \\
\hline Germany & 7.35 & 0.27 & 1.48 & 5.86 & 0.41 & & 0.76 \\
\hline Rest of the World & 5.25 & 0.32 & 0.70 & 11.49 * & 0.20 & & 0.10 \\
\hline France & 4.86 & 0.24 & 1.55 & 5.86 & 0.52 & & 0.73 \\
\hline United Kingdom & 4.30 & 0.28 & 1.28 & 5.86 & 0.56 & & 0.70 \\
\hline Italy & 3.85 & 0.25 & 1.27 & 5.86 & 0.59 & & 0.71 \\
\hline China & 2.86 & 0.22 & $0.70\left(^{*}\right.$ & 18.58 & 0.47 & & 0.10 \\
\hline Brazil & 2.29 & 0.09 & 1.00 & 13.73 & 0.42 & & 0.23 \\
\hline Canada & 2.06 & 0.33 & 1.30 & 5.10 & 0.84 & & 0.82 \\
\hline Spain & 1.93 & 0.26 & 1.35 & 5.86 & 0.79 & & 0.56 \\
\hline Mexico & 1.40 & 0.29 & 0.72 & 14.26 & 0.56 & & 0.26 \\
\hline India & 1.34 & 0.13 & $0.70\left(^{*}\right)$ & 33.44 & 2.79 & & 0.07 \\
\hline Australia & 1.32 & 0.17 & 1.13 & 5.30 & 0.94 & & 0.76 \\
\hline Netherlands & 1.31 & 0.48 & 1.51 & 5.86 & 0.89 & & 0.75 \\
\hline Russian Federatio & 1.09 & 0.28 & 0.48 & 12.47 & 0.63 & & 0.24 \\
\hline Argentina & 0.94 & 0.11 & 1.02 & 12.40 & 0.66 & & 0.39 \\
\hline Switzerland & 0.91 & 0.31 & 1.70 & 0.68 * & 1.56 & & 0.88 \\
\hline Belgium & 0.85 & 0.73 & 1.61 & 5.86 & 0.99 & & 0.80 \\
\hline Sweden & 0.80 & 0.39 & 1.61 & 5.86 & 1.00 & & 0.71 \\
\hline Austria & 0.72 & 0.35 & 1.57 & 5.86 & 1.02 & & 0.79 \\
\hline Turkey & 0.61 & 0.25 & 0.62 & 12.20 & 0.75 & & 0.21 \\
\hline Indonesia & 0.59 & 0.32 & 0.60 & 9.88 & 0.81 & & 0.10 \\
\hline Denmark & 0.58 & 0.35 & 1.50 & 5.86 & 1.05 & & 0.82 \\
\hline Hong Kong, China & 0.52 & 1.39 & 1.70 & 0.00 & 1.74 & & 0.76 \\
\hline Norway & 0.50 & 0.36 & 1.67 & 4.04 & 1.24 & & 0.90 \\
\hline Thailand & 0.49 & 0.49 & 0.64 & 18.00 & 0.91 & & 0.21 \\
\hline Poland & 0.47 & 0.27 & 0.65 & 15.55 & 0.81 & & 0.25 \\
\hline Saudi Arabia & 0.47 & 0.36 & $0.70\left(^{*}\right.$ & 12.48 & 0.78 & & 0.37 \\
\hline South Africa & 0.47 & 0.24 & $0.70\left(^{*}\right.$ & 8.30 & 0.92 & & 0.29 \\
\hline Finland & 0.41 & 0.34 & 1.39 & 5.86 & 1.10 & & 0.70 \\
\hline Greece & 0.40 & 0.19 & 1.08 & 5.86 & 1.10 & & 0.48 \\
\hline Portugal & 0.36 & 0.34 & 0.97 & 5.86 & 1.11 & & 0.50 \\
\hline Israel & 0.32 & 0.39 & 1.65 & 7.55 & 1.00 & & 0.60 \\
\hline Iran, Islamic Rep. & 0.32 & 0.21 & 0.48 & 4.90 & 1.21 & & 0.18 \\
\hline Colombia & 0.31 & 0.19 & $0.70\left(^{*}\right.$ & 11.70 & 0.85 & & 0.20 \\
\hline Venezuela, RB & 0.29 & 0.24 & 0.71 & 12.28 & 0.84 & & 0.20 \\
\hline Malaysia & 0.29 & 1.00 & $0.70\left(^{*}\right.$ & 9.18 & 0.93 & & 0.26 \\
\hline Singapore & 0.29 & 1.62 & 2.02 & 0.16 & 1.78 & & 0.67 \\
\hline Ireland & 0.26 & 0.63 & 1.29 & 5.86 & 1.14 & & 0.72 \\
\hline Egypt, Arab Rep. & 0.25 & 0.22 & 0.22 & 27.60 & 2.05 & & 0.11 \\
\hline Philippines & 0.25 & 0.48 & 0.67 & 11.22 & 0.88 & & 0.12 \\
\hline
\end{tabular}




\section{TABLE 2: DATA AND SIMULATION RESULTS}

\begin{tabular}{|c|c|c|c|c|c|c|c|}
\hline \multirow[t]{2}{*}{ Country Name } & $\begin{array}{l}\text { Size } \\
\text { GDP as \% of } \\
\text { World GDP }\end{array}$ & $\begin{array}{l}\text { Trade Volume } \\
\text { Imports /GDP }\end{array}$ & $\begin{array}{l}\text { Relative Price } \\
\text { Consumption / } \\
\text { Mach. \& Equipt }\end{array}$ & $\begin{array}{l}\text { Tariff (in \%) } \\
\text { Mean across } \\
\text { goods }\end{array}$ & $\begin{array}{l}\text { Welfare Gain } \\
\text { of eliminating } \\
\text { tariffs, in percent }\end{array}$ & $\begin{array}{r}\text { Per Capite } \\
\text { PPP Adju } \\
\text { US }=1\end{array}$ & $\begin{array}{l}\text { GDP } \\
\text { sted }\end{array}$ \\
\hline & $Y_{i} \quad[1]$ & $V_{i}[2]$ & $\mathrm{P}_{\mathrm{i}} \quad[3]$ & $100 \times\left(1-\Omega_{\mathrm{i}}\right)$ & [5] & $y_{i}$ & [6] \\
\hline Chile & 0.23 & 0.29 & 0.82 & 10.25 & 0.91 & & 0.28 \\
\hline Pakistan & 0.20 & 0.18 & 0.76 & 39.90 & 5.16 & & 0.06 \\
\hline New Zealand & 0.19 & 0.26 & 1.29 & 4.84 & 1.25 & & 0.61 \\
\hline Peru & 0.18 & 0.16 & 0.72 & 13.30 & 0.88 & & 0.15 \\
\hline Czech Republic & 0.18 & 0.60 & 0.52 & 7.04 & 1.09 & & 0.43 \\
\hline Algeria & 0.16 & 0.27 & 0.70 & 24.60 & 1.63 & & 0.16 \\
\hline Hungary & 0.15 & 0.46 & 0.52 & 13.42 & 0.89 & & 0.35 \\
\hline Ukraine & 0.15 & 0.47 & 0.24 & 10.20 & 0.94 & & 0.12 \\
\hline Bangladesh & 0.14 & 0.15 & 0.68 & 21.30 & 1.27 & & 0.05 \\
\hline Romania & 0.12 & 0.31 & 0.38 & 16.03 & 0.95 & & 0.21 \\
\hline Morocco & 0.11 & 0.30 & 0.50 & 30.77 & 2.68 & & 0.11 \\
\hline Nigeria & 0.11 & 0.41 & 0.61 & 24.06 & 1.58 & & 0.03 \\
\hline Vietnam & 0.08 & 0.25 & 0.28 & 15.15 & 0.94 & & 0.06 \\
\hline Belarus & 0.08 & 0.62 & 0.30 & 12.63 & 0.92 & & 0.20 \\
\hline Kazakhstan & 0.07 & 0.40 & 0.37 & $1.15 *$ & 1.71 & & 0.16 \\
\hline Slovak Republic & 0.06 & 0.64 & 0.43 & 6.88 & 1.14 & & 0.32 \\
\hline Tunisia & 0.06 & 0.45 & 0.40 & 31.17 & 2.77 & & 0.18 \\
\hline Sri Lanka & 0.05 & 0.41 & 0.57 & $7.67^{*}$ & 1.09 & & 0.10 \\
\hline Simple Average & 1.67 & 0.370 & 0.94 & 11.26 & 1.12 & & 0.41 \\
\hline Weighted Average & & 0.210 & & 7.62 & 0.50 & & \\
\hline
\end{tabular}

Sources:

[1]: Share in world gdp. GDP in current dollars. From WDI 2002 cdRom, average 1994-2000

[2]: $0.5^{\star}$ (Exports+Imports)/GDP, all in current dollars. From WDI 2002 cdRom, average 1994-2000

[3]: Price of machinery and equipment relative to consumption, from benchmark PWT year 1996.

Average of other countries for ROW. The countries marked with $\left(^{*}\right)$ are not in the 1996 PWT benchmark, so we use the average for the other countries. [3] displays the reciprocal of this number.

[4]: Average 1996-2000 ad valorem tariff rate, simple average across products, from Dollar and Kraay, using worldbank database "Data on Trade and Imports Barriers", when available. When it is not available, indicated as *, import duties/imports from WDI 2002. Average of other 59 countries for ROW

[5]: Calculations described in section 9, Figure 9.2

[6]: Penn World Table average 1994-2000

The Weighted averages are GDP weighted for Trade Volume and Welfare gains, and weighted by Imports for tariffs 


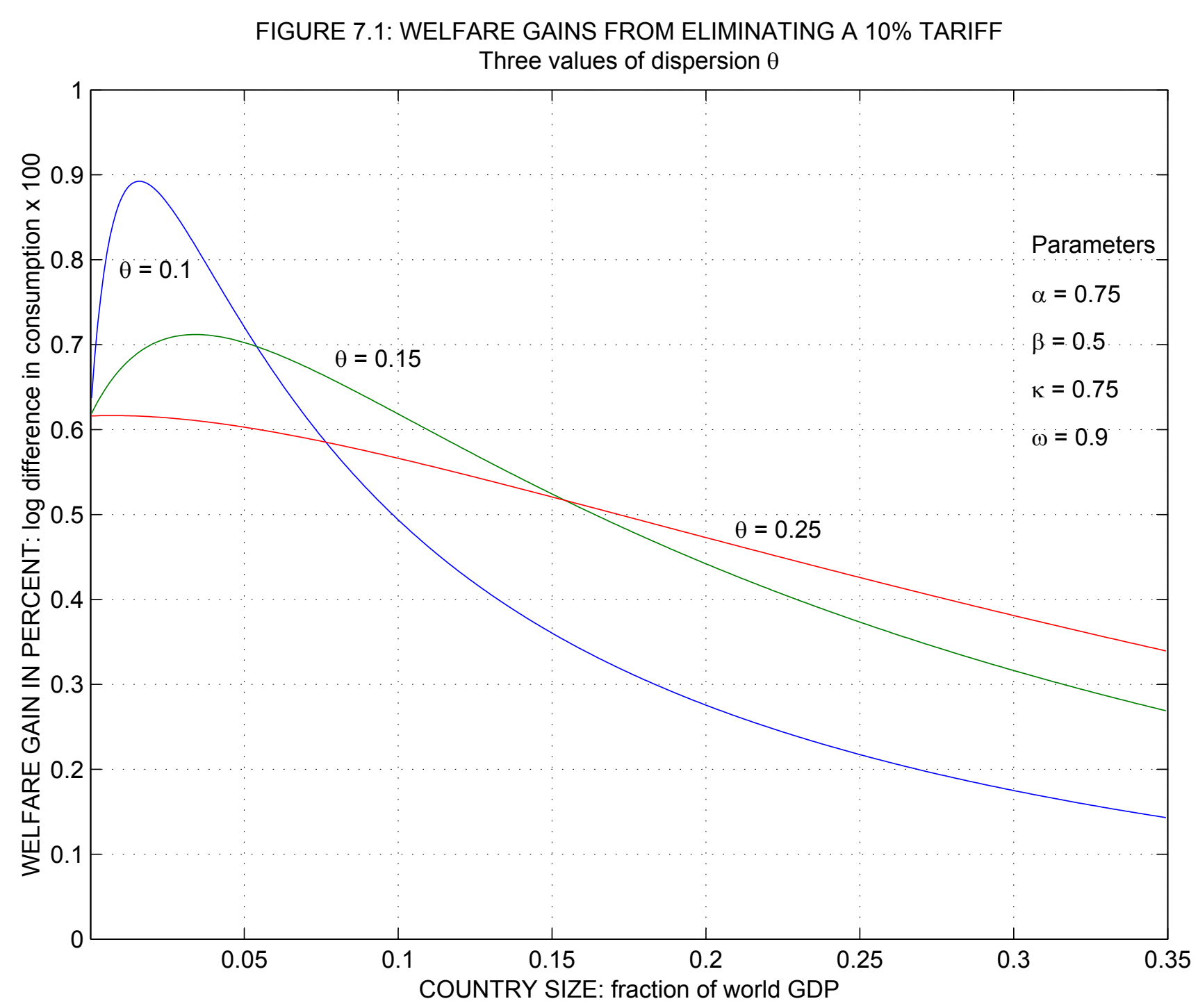


FIGURE 7.2: VOLUME OF TRADE

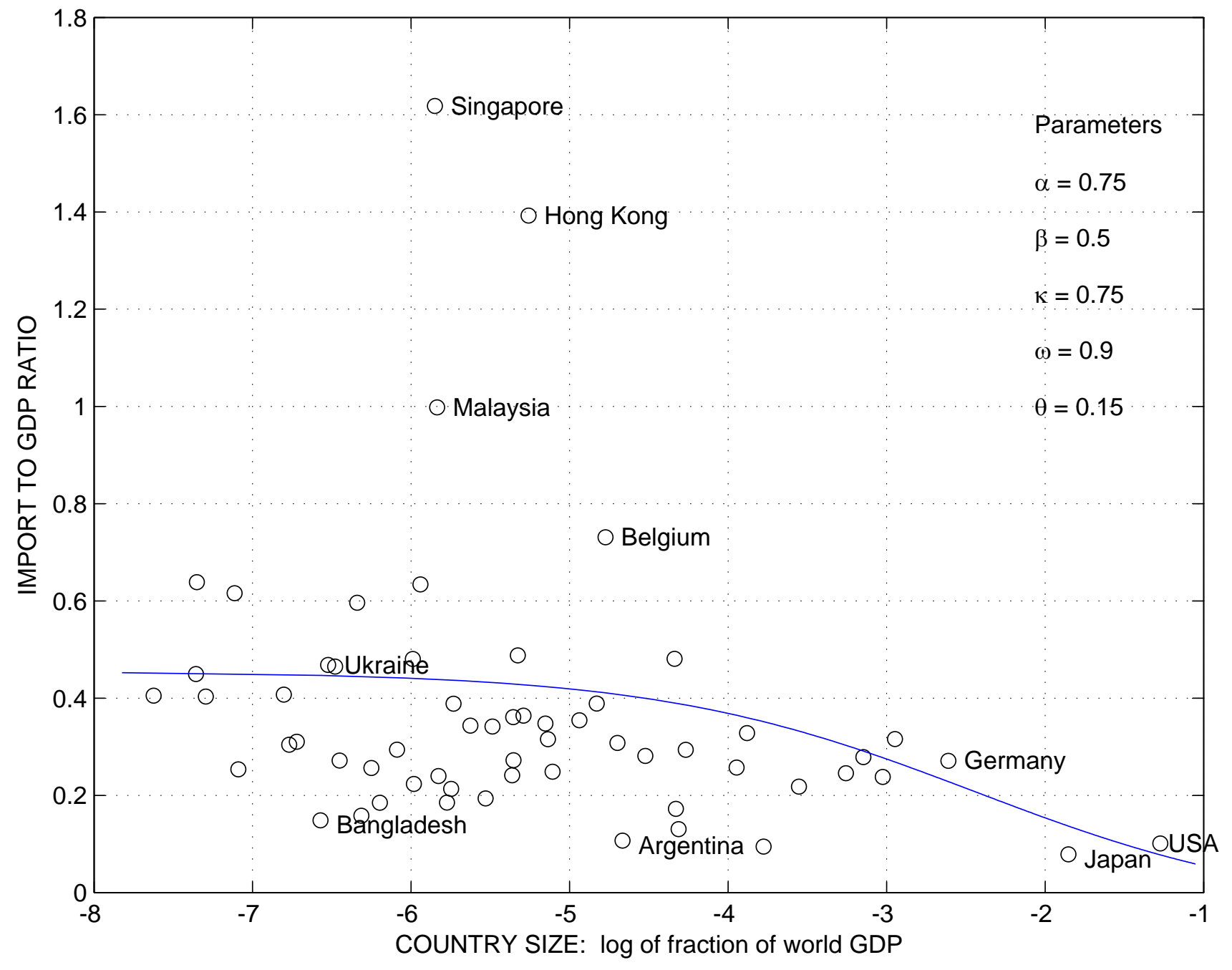


FIGURE 8.1: WAGES VERSUS SIZE

Three values of $\theta$

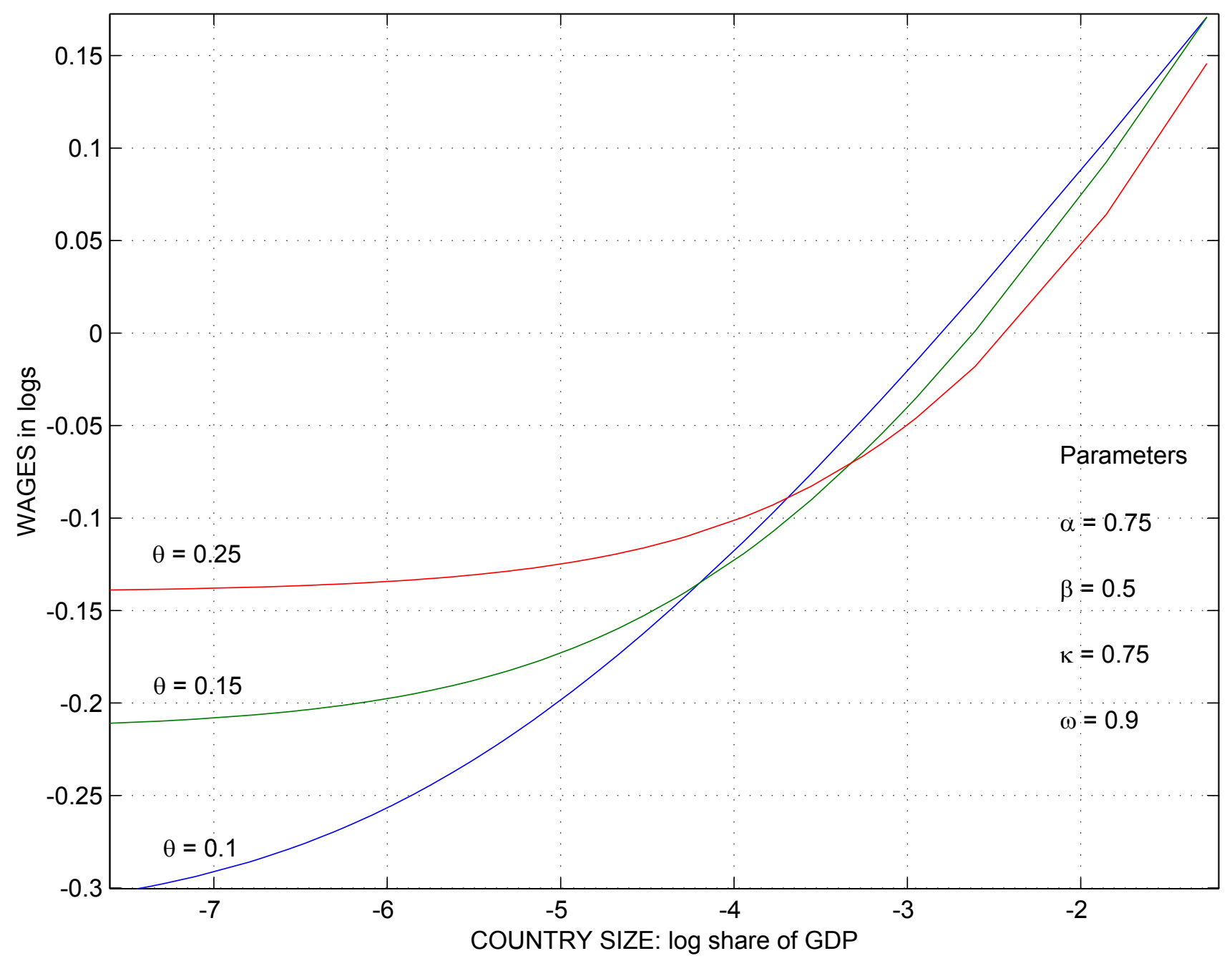


FIGURE 8.2: VOLUME OF TRADE

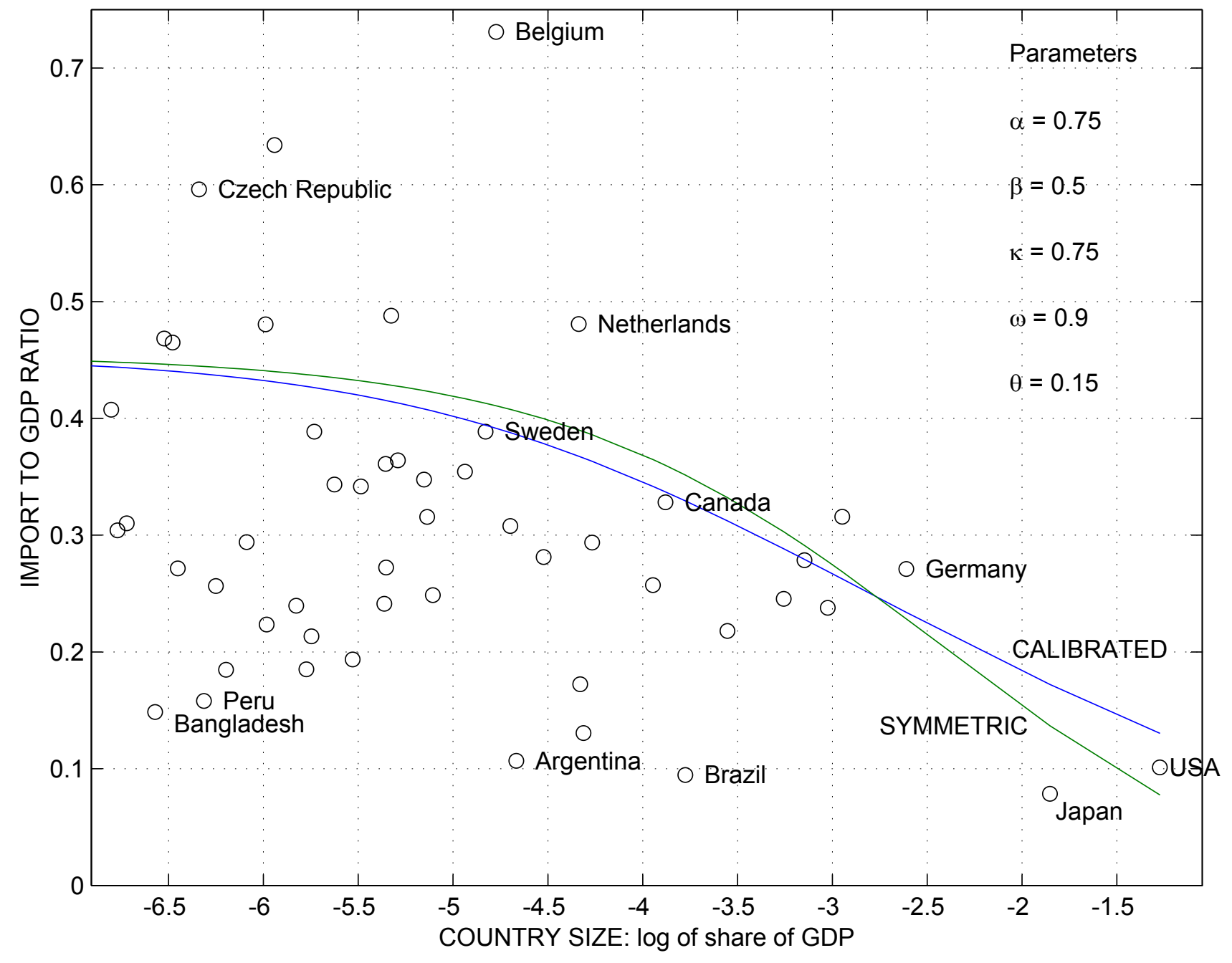


FIGURE 8.3 VOLUME VERSUS SIZE

Data (o), Model w/uniform tariffs (solid), Model w/tariffs from Table $2\left({ }^{*}\right)$

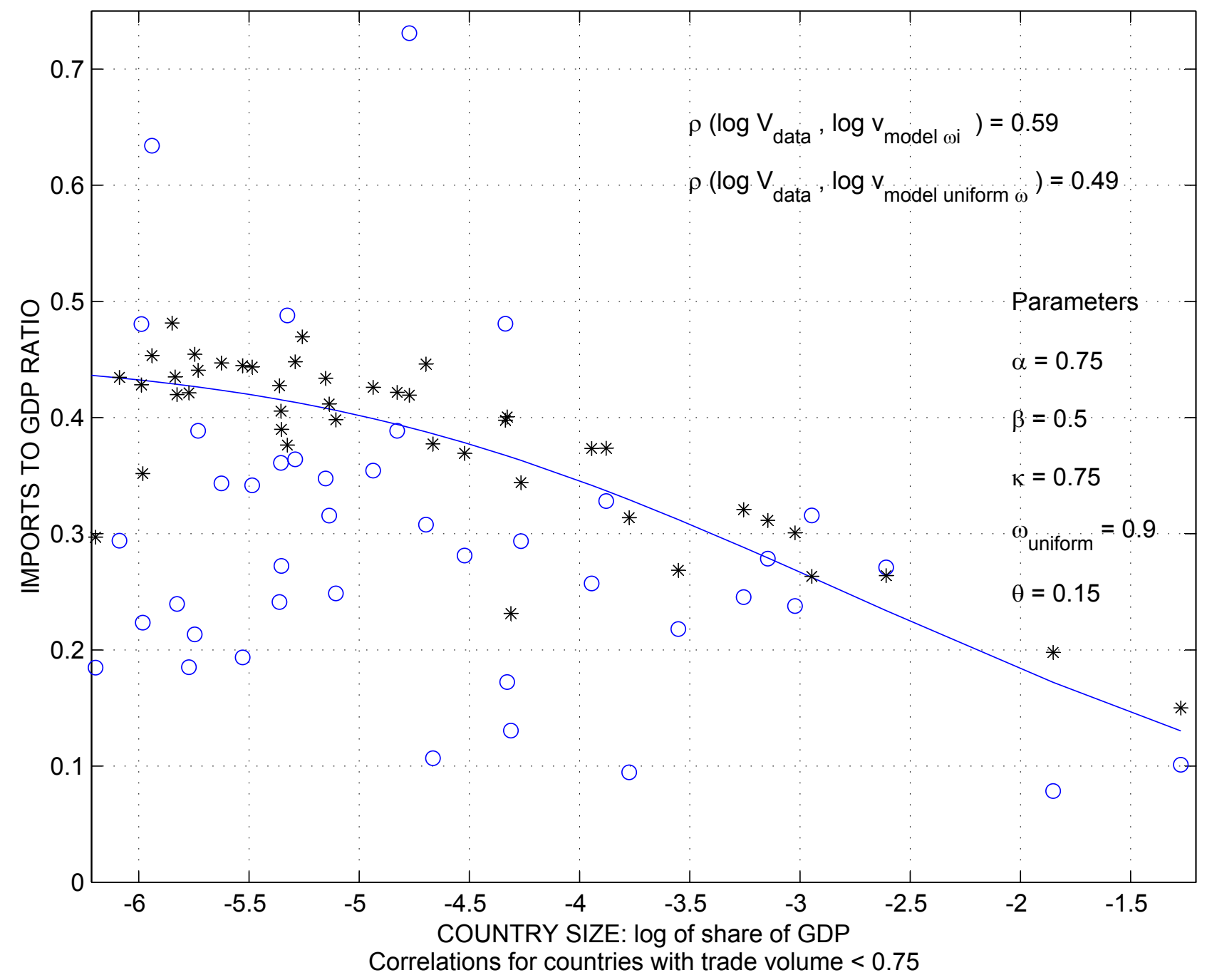


FIGURE 9.1: WELFARE EFFECTS OF TARIFF FACTOR $\omega$ FOR A SMALL OPEN ECONOMY Three values of $\theta$

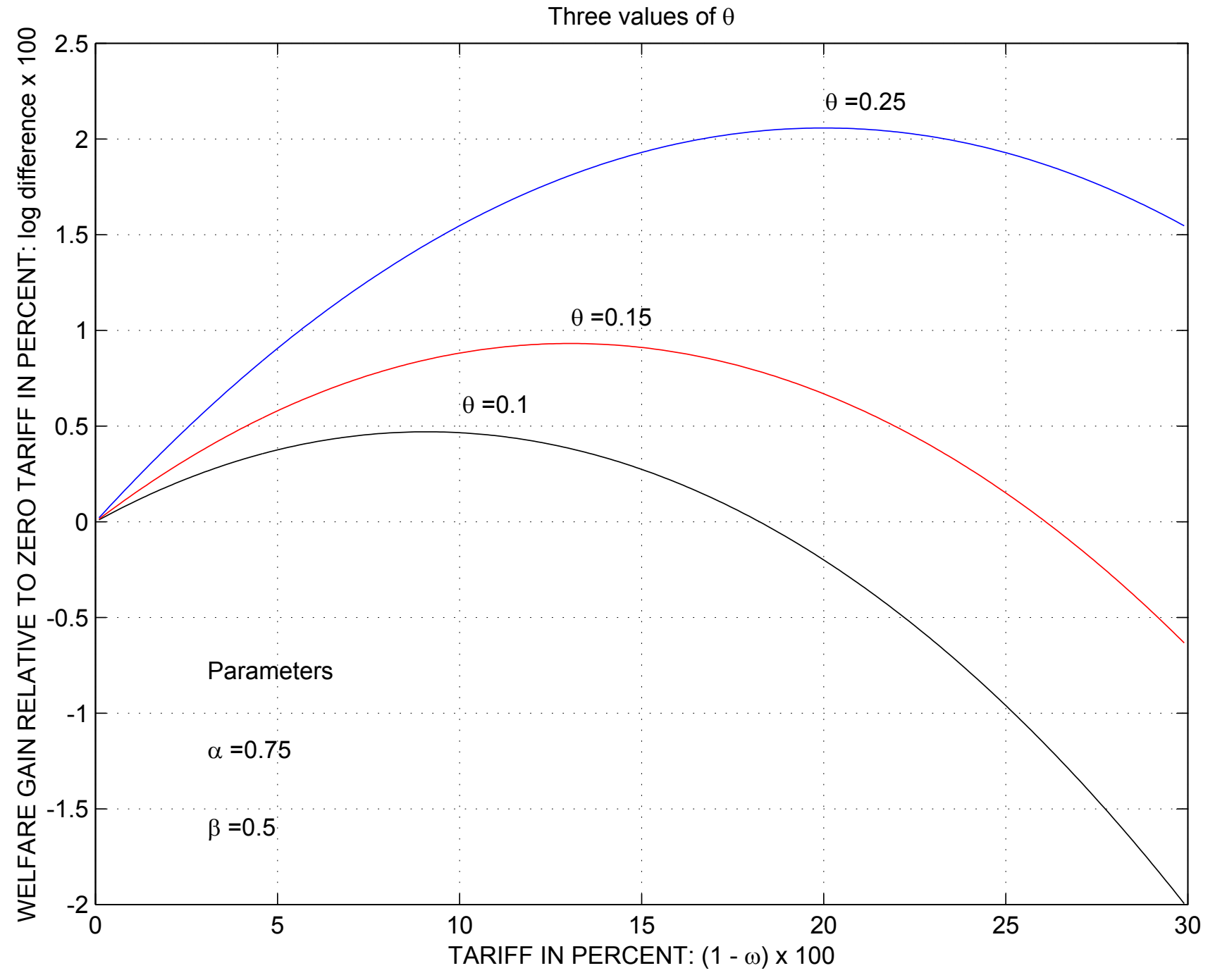


FIGURE 9.2: WELFARE GAINS FROM ELIMINATING TARIFFS

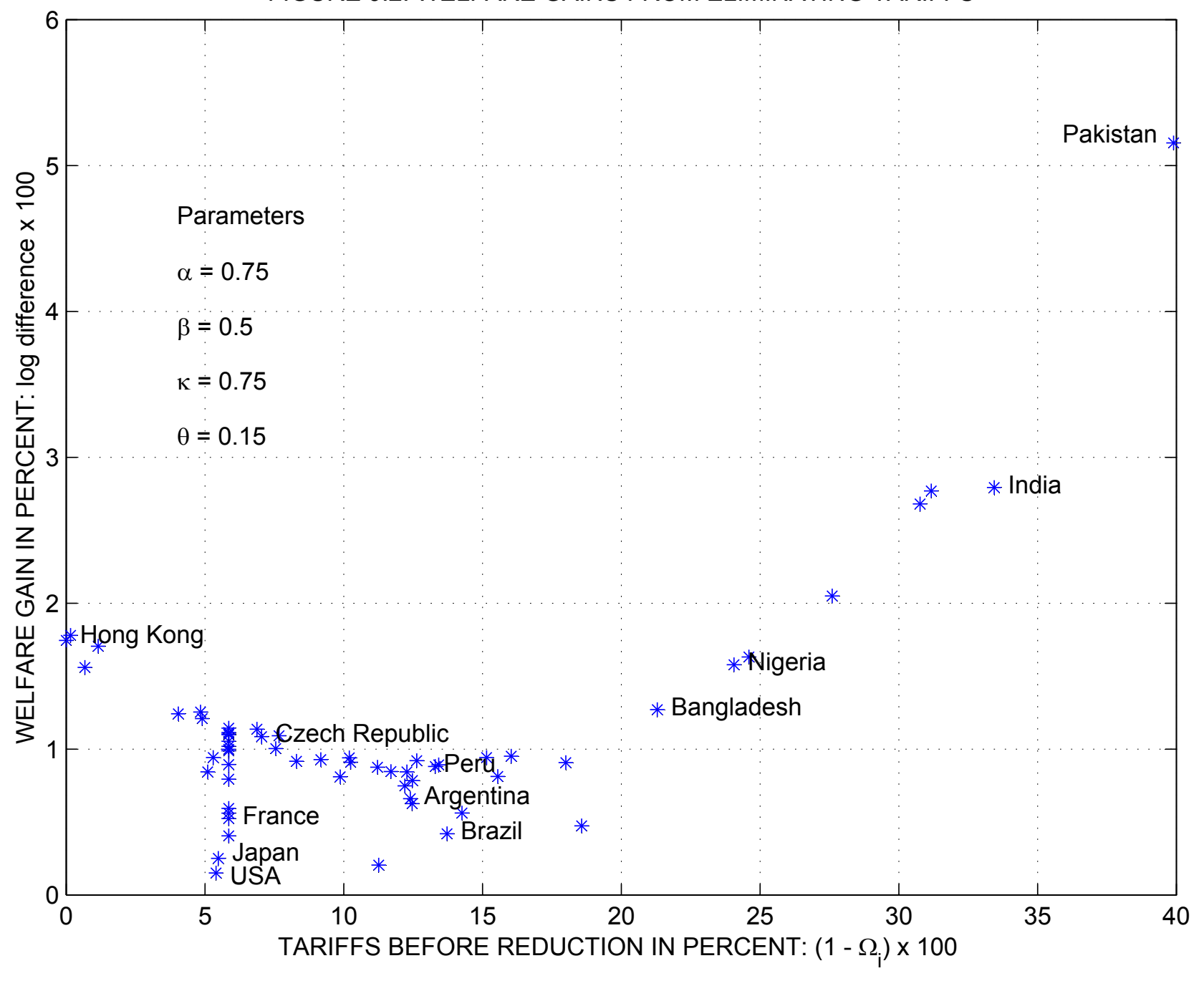


FIGURE 9.3: WELFARE GAINS FROM ELIMINATING TARIFFS

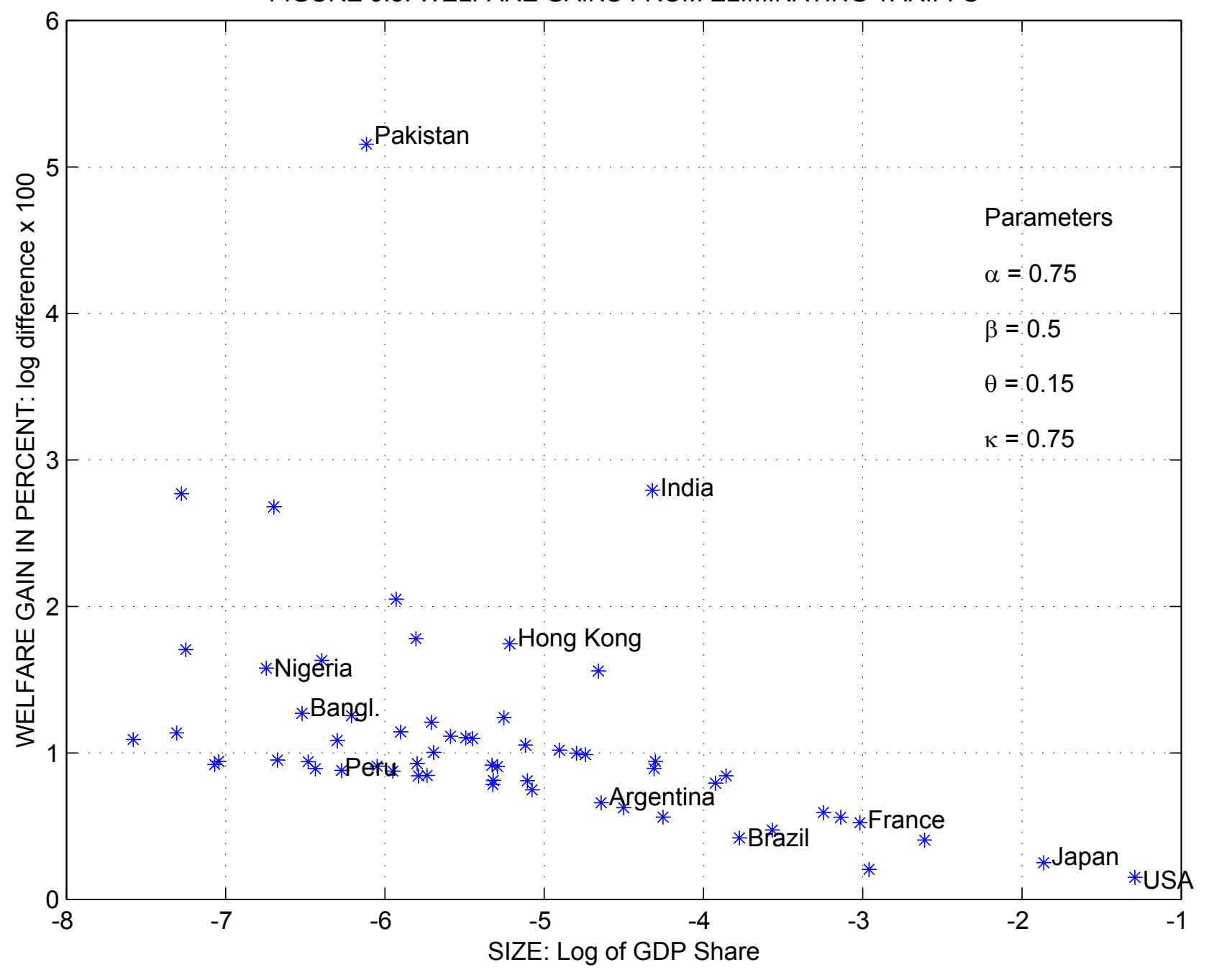


FIGURE 10.1: WAGES IN THE TWO CALIBRATIONS

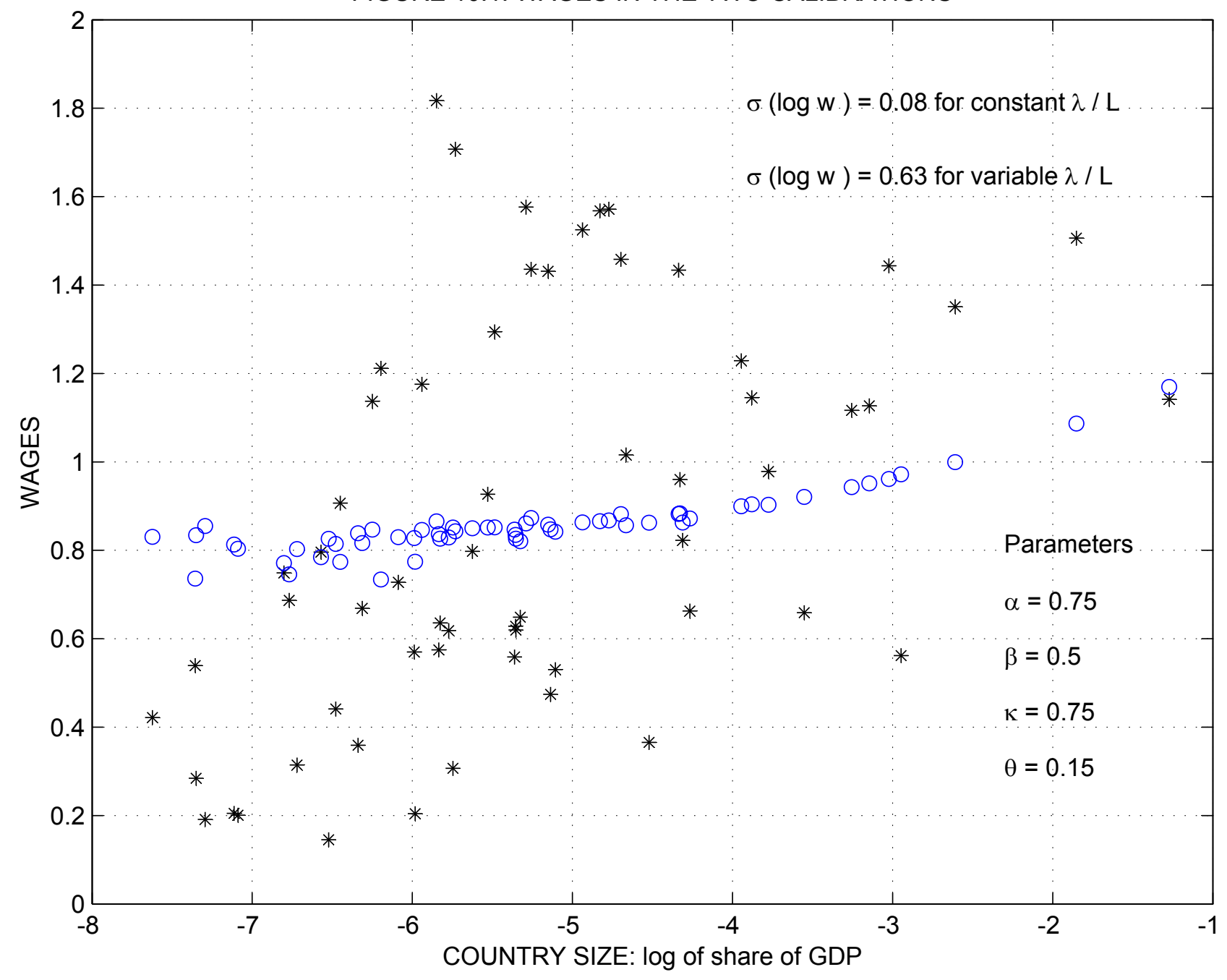

